\title{
A gestão de territórios sustentáveis e as ações estratégias das universidades
}

\author{
The management of sustainable territories and strategies in universities areas
}

\author{
Aloísio Ruscheinsky ${ }^{1}$ \\ Marjorie Fonseca e Silva Medeiros ${ }^{2}$
}

\begin{abstract}
Resumo
$\mathrm{O}$ artigo consiste numa exposição acerca das dimensões ambientais em duas universidades brasileiras, enfatizando as condições para a implementação, as barreiras e dificuldades para gerar territórios sustentáveis. A abordagem metodológica consolida-se por um percurso teórico e a coleta de dados empíricos que leva em consideração as peculiaridades e estratégias ambientais de cada instituição. Três aspectos dão rumo à abordagem proposta, como a complexidade e interdisciplinaridade, a gestão de resíduos e os indicadores de controle da qualidade ambiental. Os resultados alcançados nestas ênfases indicam o desenrolar de experiências, oportunidades, riscos e obstáculos ante as soluções para os impactos ambientais nas universidades selecionadas.
\end{abstract}

Palavras-chave: Universidade. Ações estratégicas. Sustentabilidade. Território. Gestão.

\begin{abstract}
This paper is a presentation on the environmental dimensions in two Brazilian universities, emphasizing the conditions for implementation, the barriers and difficulties to generate sustainable territories. The methodological approach is funded by a theoretical course and the collection of empirical data that takes into account the peculiarities and environmental strategies of each institution. Three emphases give the direction to the approach proposed in the article as the complexity and interdisciplinarity, waste management and environmental quality control indicators. The results indicate the development of experiences and opportunities, risks and obstacles, creativity and solutions to the environmental impacts in selected universities.

Keywords: University. Strategic actions. Sustainability. Territory. Management.
\end{abstract}

\section{Introdução}

A presente investigação aborda alguns aspectos relativos à discussão e ao processo de sensibilização ambiental na esfera universitária, de forma peculiar a ambientalização, como estratégia adotada para a construção de uma política ambiental em todos os âmbitos internos aos contextos institucionais universitários. As universidades possuem uma função social relevante na produção e socialização de conhecimentos e competências, visando contribuir para uma cidadania

\footnotetext{
${ }^{1}$ Doutor em Sociologia (USP). Professor titular do PPGCS da Unisinos; líder do grupo de pesquisa CNPq Sociedade e meio ambiente. E-mail: aloisior@unisinos.br

${ }^{2}$ Mestre em Educação; Programa de Educação Ambiental da UFRN - ProEA. E-mail: arjoriefsm@gmail.com
} 
socialmente responsável pela sustentabilidade, portanto, como organizações que se apresentam sob a perspectiva de construção de territórios sustentáveis. O objeto deste trabalho consiste em apresentar parte dos resultados de pesquisa, que tratou da inserção da dimensão ambiental nas esferas de duas universidades brasileiras. Assim, procuramos conhecer as ideias relativas à sustentabilidade que povoam parte das múltiplas atividades universitárias. A elaboração dos resultados leva também em consideração pesquisas desenvolvidas a partir da visão dos graduandos acerca de sua formação que enfatizem a dimensão ambiental.

No que diz respeito ao processo de internalização da questão ambiental nas diversas instâncias da sociedade as quais correspondem um crescente reconhecimento da legitimidade de um campo socioambiental como uma esfera pública, o planejamento estratégico nas universidades pesquisadas tem entre as metas a promoção da confiança de funcionários, estudantes, docentes, colaboradores, parceiros, fornecedores e sociedade na sua proposição de um território sustentável que preza a dimensão ambiental em suas atividades. Efetivamente, a questão da sustentabilidade ambiental passou a integrar e converteu-se em um fator emblemático de legitimação das práticas do planejamento institucional.

Os autores se associam ao escopo aludido a fim de engendrar uma publicação abrangente acerca da sustentabilização ${ }^{3}$ das instituições de ensino superior. Sendo ambiciosos, pode-se projetar entre os intuitos do texto a tentativa de descrever o estado atual do conhecimento e das práticas em curso. Ao mesmo tempo, pode-se também almejar abrir brechas para novos horizontes neste campo dos cuidados com os bens naturais, pois a rápida expansão de políticas ambientais parece um imperativo diante da velocidade de depredação ambiental. Ações de planejamento e de educação e gestão ambiental vêm ganhando um espaço crescente também nas universidades, a exemplo do que ocorre em outros espaços institucionais do país e em diferentes camadas e setores da sociedade, com o desenvolvimento de outra consciência ecológica e aumento da preocupação com a sustentabilidade do planeta ${ }^{4}$.

Para o desenvolvimento da pesquisa, utilizou-se como metodologia a pesquisa documental e a participação dos autores em múltiplas atividades referentes à dimensão ambiental nas respectivas universidades, tais como debates, comissões, reuniões, fóruns e na elaboração de diretrizes. Essa participação dos autores no que se refere à dimensão ambiental nas respectivas universidades tem

\footnotetext{
${ }^{3}$ Entre outros autores, sustentabilização curricular e da investigação ou das construções no campus são noções usadas por YÁNEZ, Raiza et al. Aproximación al redimensionamiento de la Ingeniería desde la perspectiva del desarrollo sustentable y el pensamiento complejo. Ingeniería Industrial, v. III, n. 11, p. 87-94, 2013. Raúl M. Halac; Mariela Marchisio, no texto de 2008, expõe que "Los campus universitarios como espacios de producción y multiplicación de la construcción Sustentable" abordam o planejamento da sustentabilização dos espaços das universidades.

4 "Poucas pessoas, em qualquer lugar do mundo, podem continuar sem consciência do fato de que suas atividades locais são influenciadas, e às vezes até determinadas, por acontecimentos ou organismos distantes” (GIDDENS, 1997, p. 23).
} 
como elementos para colher informações por métodos empregados na pesquisa os seguintes indicadores: a temática ambiental conjugada ao interdisciplinar; a gestão integrada de resíduos; a qualidade ambiental; o controle da água para o consumo.

Trata-se de uma investigação de cunho quanti-qualitativo, referindo-se aos dados produzidos e disponibilizados pelo setor de gestão ambiental e à participação dos autores como sujeitos participantes e ativos nos processos decisórios, bem como observadores de processos e conflitos com suas múltiplas possibilidades. As observações de campo ocorreram tanto nos espaços próprios da atividade acadêmica, como laboratórios, bem como no acompanhamento de reuniões e articulações. A seleção de dados quantitativos, para completar a dupla estratégia metodológica, contou com a colaboração de diversos setores que produzem estatísticas relativas às questões ambientais inerentes as suas atividades profissionais. Neste texto, como uma terceira dimensão metodológica, também estamos trabalhando com a discussão e os resultados provenientes de relatos, ou entrevistas informais, apresentados por cerca de dez interlocutores que são nossos colegas de trabalho.

Parece importante destacar que se tomam como referência dados relativos a duas universidades, porém, não se tem o intuito de um estudo comparativo, que poderia concorrer para estabelecer critérios de qual delas é melhor ou possui uma política mais adequada à legislação vigente. As quatro seções do presente texto referem-se a um contexto cambiante ou em movimento, às interações sociais e aos ajustes institucionais em face de nexos contemporâneos entre sociedade e natureza, entre atores socioambientais e políticas na universidade.

A estrutura proposta para o desenvolvimento do artigo se centra em três ênfases: a complexidade da temática ambiental entendida e operada de forma interdisciplinar em diversas atividades; a breve narrativa acerca das experiências de tratamento dos resíduos gerados e dos respectivos impactos numa ótica de gestão integrada; as práticas a partir do olhar dos indicadores de qualidade ambiental, destacando-se os mecanismos de controle a propósito da qualidade da água. Essa tripla abordagem de alguma forma sumariza, no entender dos autores, provavelmente as principais estratégias a serem observadas nas instituições de ensino quando se trata da ambientalização.

\section{$O$ contexto da investigação}

A seleção dos termos de investigação e a seleção do horizonte teórico e metodológico implica em todas as circunstâncias em opções e decisões, por isso o leitor encontrará nos 
argumentos aqui apresentados uma ótica de ativistas da política ambiental das respectivas universidades. E, no presente caso, advoga-se uma perspectiva epistemológica que possui um compromisso com a ampliação ou radicalização da preocupação com a dimensão ambiental no interior das atividades pertinentes à gestão do espaço universitário da Unisinos (Universidade do Vale do Rio dos Sinos), no Sul do Brasil, e da UFRN (Universidade Federal do Rio Grande do Norte), no Nordeste. Todavia, devido ao âmbito do estudo e à perspectiva da abordagem metodológica, a investigação, de forma alguma, pode ser considerada como representativa do que está em curso nas demais instituições universitárias.

Em Natal estão localizados dois dos nove campi da UFRN: o Campus Universitário Central e o da Saúde 5 . O Campus Central pode ser comparado a um pequeno núcleo urbano, pois ocupa uma área de 123 hectares dentro da cidade (SALES; LISBOA; FREIRE, 2009), por onde circulam diariamente aproximadamente 45.000 pessoas entre professores, discentes, funcionários, visitantes e contratados. A sua localização, contígua ao Parque Estadual Dunas do $\mathrm{Natal}^{6}$, considerado o maior parque urbano sobre dunas do Brasil, requer cuidados em ações que possam provocar impactos no meio ambiente, pela importância dessa unidade de conservação, tanto na recarga do lençol freático da cidade, quanto na purificação do ar, além da diversidade que abriga da fauna e flora, de grande valor bioecológico, que inclui diversas espécies em processo de extinção (PARQUE DAS DUNAS, 2015).

Por sua vez, a Unisinos possui o seu campus principal em São Leopoldo e outro em Porto Alegre $^{7}$. O campus em São Leopoldo é um lugar de convivência num espaço em cujo planejamento coexistem natureza, ciência e tecnologia. O espaço em consideração localiza-se na região metropolitana da capital gaúcha e que se consolida como um dos importantes polos econômicos, além de ser reconhecido como berço da colonização alemã.

Possui uma área de 90,55 hectares com área construída de aproximadamente 190 mil metros quadrados ${ }^{8}$. Além disso, possui lagos, jardins, áreas de preservação ecológica e algumas espécies de

\footnotetext{
${ }^{5}$ Em Natal há ainda algumas unidades isoladas, sendo os demais campi em municípios do interior, além de estar presente em 20 unidades e polos de EaD em municípios do Rio Grande do Norte, Paraíba, Pernambuco e Alagoas. Por quase 40 anos foi a única universidade do estado.

${ }^{6}$ De acordo com Sales; Lisboa; Freire (2009, p. 80), "Devido à construção do Campus Universitário, no início da década de 1970, houve destruição parcial da vegetação nativa. Até os dias atuais, a área do Campus vem sofrendo grande adensamento urbano, principalmente na última década. Da vegetação original, restaram apenas alguns fragmentos distribuídos irregularmente. É relevante, portanto, investigar a composição e diversidade de espécies de Squamata destes fragmentos e compará-las com a da área não urbanizada do PEDN (Parque Estadual das Dunas do Natal)". ${ }^{7}$ Porém, está presente também em unidades e polos EaD em cinco grandes cidades do Rio Grande do Sul, como também em Florianópolis, Curitiba e São Paulo.

${ }^{8}$ Os dados acerca das instalações da Unisinos foram coletados nos múltiplos contatos e também extraídos de diferentes pontos do site www.unisinos.br. A rede de serviços, por meio de parcerias, compõe-se de lojas entre livrarias, confecções, farmácia, revistarias, fotocopiadoras, restaurantes, cafeterias, corretoras, agências de viagem, salão de beleza, agências bancárias e uma agência dos Correios.
} 
animais que expressam a dimensão socioambiental. Possui uma das maiores bibliotecas universitárias da América Latina, contando com um acervo de 220 mil títulos e 700 mil itens. Em 2004, tornou-se a primeira universidade da América Latina, e entre um pequeno grupo no mundo, a obter a certificação ISO 14001, concedida a organizações pelos cuidados com o ambiente natural, com o controle dos impactos ambientais de suas atividades, produtos e serviços. Na Unisinos, em São Leopoldo, encontra-se o maior polo de inovação em informática do Sul do país, com diversas empresas de porte na área de Tecnologia da Informação. Entre outras, uma unidade da maior fabricante mundial de microprocessadores e circuitos integrados.

A UFRN, como uma instituição pública autárquica, está sujeita às instruções do Decreto 5.940/2006, cujo teor trata da separação dos resíduos recicláveis descartados pelos órgãos públicos federais, na fonte geradora, e a sua destinação às associações e cooperativas dos catadores de materiais recicláveis. Além dessa obrigação legal, ambas as universidades atentam para a Política Nacional de Resíduos Sólidos (Lei 12.305/2010), que inclui: a saúde como qualidade ambiental; a não geração, redução, reutilização, reciclagem e tratamento dos resíduos sólidos; adoção de padrões sustentáveis de produção e consumo de bens e serviços; capacitação técnica continuada dos funcionários na área de resíduos sólidos; a integração dos catadores nas ações que envolvam a responsabilidade socioambiental.

Há uma possível discussão acadêmica e por vezes apresenta-se como causa de polêmica acerca da natureza da Unisinos: privada ou pública não estatal e sujeita à lei 12305/2010 acima delineada. Além disso, a busca pela certificação da NBR ISO 14001 reporta-se a informações que refletem em estratégias diferentes na condução da política ambiental das universidades.

Enfim, o contex to histórico em que foi gestado o presente texto foi a apresentação na UFRN, especialmente aos agentes sociais que atuam na gestão, das questões que formam a espinha dorsal do livro “Ambientalização...”(RUSCHEINSKY, 2014): as mudanças institucionais como um evento histórico a partir de uma ação coletiva em consequência das lógicas que remetem a um longo e conflituoso debate público, resultando no amparo de políticas visando territórios ambientalmente sustentáveis. A partir das contribuições recolhidas no mencionado livro é possível desenhar um panorama bastante amplo de políticas de sustentabilidade elaboradas por diferentes universidades. Por outro lado, nunca será demais retornar às pesquisas e às reflexões para um esclarecimento fundamental do estatuto epistemológico do que se denomina de ambientalização ${ }^{9}$. Essa questão também se colocava como objetivo do simpósio do qual participou um dos autores do presente

\footnotetext{
${ }^{9}$ Para Lopes (2004, p. 34), "O termo “ambientalização" é um neologismo semelhante a alguns outros usados nas Ciências Sociais para designar novos fenômenos ou novas percepções de fenômenos vistos da perspectiva de um processo".
} 
texto, ao propor-se a compreensão dos fundamentos epistemológicos da categoria em uso na academia no contexto da pesquisa e do ensino, porém, ao mesmo tempo conectado com gestão, pesquisa e extensão.

Da parte dos autores, trata-se de texto de relevância para o campo das ciências ambientais, trazendo à luz as ações realizadas e direcionadas à sustentabilidade em universidades, as quais testemunham, nas últimas décadas, expressivas mudanças institucionais e políticas que impactam diretamente suas práticas no que se refere à temática em tela.

A reflexão sobre a temática ambiental por vezes se defronta com paradoxos, como é o caso de realizar a crítica à concepção de desenvolvimento sustentável e ao mesmo tempo não poder desvencilhar-se das questões que envolvem o desenvolvimento territorial. Nesse sentido,

uma das evidências mais palpáveis dessa convergência do planejamento e da sustentabilidade é a proposta de cidades sustentáveis da Organização das Nações Unidas, que surgiu ao início da década de 1990. Sua adoção por mais de trinta países torna urgente uma leitura crítica do desenvolvimento sustentável e da natureza da ambientalização do discurso do planejamento, que contribua para se avançar rumo à construção de uma economia política do espaço e a uma prática de planejamento, que instrumentalize a participação social em uma perspectiva transformadora. (LIMONAD, 2013, p. 123).

A expressão dos obstáculos e das dificuldades observadas nas duas universidades a partir de bases sociológicas permite enfatizar a relevância de associar duas categorias, tais como territórios sustentáveis e imaginários ${ }^{10}$ sociais sustentáveis.

\section{A temática ambiental entendida e operada de forma interdisciplinar}

Planejar e abordar a temática ambiental de forma interdisciplinar ainda constitui um desafio imenso, especialmente no ensino universitário ${ }^{11}$, que está calcado na formação de especialistas. Isso

\footnotetext{
${ }^{10}$ Para um detalhamento desse conceito recorremos a Leff (2014, p. 347): "En los imaginarios sociales arraiga lo real de la Tierra, generando formas del ser en los que se despliegan modos de pensar y de sentir el mundo; prácticas, hábitus y costumbres que no reflejan la clarividencia ni la verdad de lo real, sino que crean mundos de vida, que no siempre se traducen en formaciones discursivas. Sin embargo, cuando esos imaginarios se enuncian lingüísticamente, adquieren un carácter colectivo y dialógico en donde se expresa la fuerza imaginativa y prospectiva de un pueblo o comunidad en la invención de nuevos mundos de vida".

${ }^{11}$ Em 2002 foi constituída a Rede ACES (Ambientalização Curricular do Ensino Superior) com o intuito de levar a cabo um projeto comum para a inserção da temática ambiental no Ensino Superior, com a mediação do compartilhamento de conhecimentos, discutindo propostas acerca de programas, estratégias e instrumentos acerca da ambientalização curricular.
} 
de alguma forma está em dissonância com universidades e institutos de pesquisas, bem como de discentes que atestam o interesse na temática ambiental sob a ótica interdisciplinar.

De acordo com Martínez-Alier e outros (2015), as estratégias de interdisciplinaridade se postulam há algumas décadas, contemplando entre outros aspectos: a) reelaboração epistemológica de cada ciência à luz das incertezas proporcionadas a partir das questões ambientais; b) uma rearticulação dos conhecimentos que endossam novas ênfases em função dos mais proeminentes e complexos problemas ambientais; c) articulação de investigadores para a cooperação competente, instando a eficiência na comunicação interdisciplinar.

Ao mesmo tempo há que reconhecer as contribuições para a compreensão da problemática ambiental e de vacilações políticas na interpretação. Foladori e Taks (2004, p. 323) vão afirmar que a antropologia pode contribuir em

desmistificar os preconceitos sobre a relação das sociedades com seus ambientes naturais - preconceitos tais como os mitos da existência de um vínculo harmonioso entre sociedade e natureza nos tempos pré-industriais, o da tecnologia moderna como causa última da crise ecológica ou o do papel sacrossanto da ciência como guia em direção à sustentabilidade.

A pretensão da análise empreendida no presente texto está deliberadamente orientada para a implementação de práticas em acordo com os requisitos da sustentabilidade em sentido transversal. Por isso, considera-se o olhar do que é dito e do que é feito tanto no campo das políticas de gestão das universidades quanto nas razões postas pela produção do conhecimento a partir das diferentes ciências, especialmente em suas conexões sociais (MATHIEU, 2006). Metodologicamente também, na medida em que a abordagem interdisciplinar ou a ótica transdisciplinar propõe-se a subsidiar o complexo tema da utopia e sua ação, envolvendo o uso de escala e compreensão do poder e de um conjunto de conflitos inter-relacionados (FOLLARI, 2001; MATHIEU, 2006). Ainda do ponto de vista metodológico, como se mobilizam as informações e de que modo operam as dimensões antropológicas como possibilidade da implementação de uma política ambiental inerentemente complexa, equacioanando eixos e questões contraditórias.

Floriani (2004, p.105-106) propõe passos em que se podem sintetizar algumas etapas básicas da construção interdisciplinar no campo da pesquisa, contemplando a temática ambiental na coleta de dados, na seleção das informações e na interpretação: elaboração preliminar de discussões e explicitação de transversalidades temáticas; localização das principais práticas e conflitos socioambientais; eleição de prioridades de pesquisa e metodologia de comum acordo; aplicação dos instrumentos e validação dos dados; interpretação e resultados finais. 
A menção às barreiras e dificuldades, aos riscos e obstáculos para erigir uma perspectiva interdisciplinar e a lógica de territórios sustentáveis possui implicações políticas para dentro e para além das universidades. Para o interior, esse movimento se vislumbra de alguma forma um encontro de variados saberes, em vez da supremacia ou exclusividade do conhecimento científico. Para além, ressalte-se o reconhecimento das lutas socioambientais como instrumento político de formulação de alternativas.

Ainda, de acordo com Floriani e com o que se visibiliza em poucos grupos de pesquisa das universidades, a interdisciplinaridade consiste numa ação do conhecimento para confrontar saberes, com o intuito de alçar outro saber mais abrangente, capaz de traduzir a complexidade das interações entre sociedades humanas e o meio natural. Sobre esse aspecto há divergências teóricas e também convergências. De acordo com Castro; Hogenboom; Baud (2015, p. 18),

A pesar de sus posiciones teoréticas y metodológicas diferentes (ver Castro, 2013), todas ellas consideran el comportamento social hacia los recursos naturales como un complejo mecanismo de interacciones formales e informales entre los agentes estatales y no estatales a través de diferentes escalas, impulsados por factores ecológicos y sociales.

Na sociedade do conhecimento existe um lugar didático para tais componentes de interação, seja sob a ótica disciplinar ou transdiciplinar, conforme endossa Ropohl (2012). Da mesma forma, se requer uma reflexão sofisticada ou a adesão à complexidade acerca das diferentes qualidades de conhecimento, de divulgação adequada e de recepção ou tradução. As associações mencionadas são constitutivas e constituintes do processo do conhecer, sendo incerta a tendência de obter sucesso em regiões de fronteira de representação da realidade. Assim, a fronteira, menos como limite intransponível, assume-se como espaço de encontro entre diferentes domínios do conhecimento, como é o caso do empreendimento da gestão ambiental destacado agora como relato da pesquisa de campo.

Um dos primeiros encaminhamentos da gestão 1999-2003 da UFRN foi a criação de uma Comissão para proceder a estudos e propor alternativas de otimização do consumo da energia elétrica. A ideia de um plano de gestão ambiental para o campus central emerge da participação de servidores na I Conferência Nacional de Educação Ambiental realizada em novembro de 1997, em Brasília, na qual um grupo de professores e técnicos iniciou um ciclo de debates para discutir as questões ambientais na universidade. Isso culminou, ao final de 1998, com a apresentação de uma proposta à reitoria de elaboração de um programa de gestão ambiental visando territórios sustentáveis. Entre as discussões situam-se os dilemas ante uma proposta paradigmática para discorrer sobre os fenômenos socioambientais sem recair nas armadilhas das dicotomias 
teoria/prática; $\quad$ indivíduo/sociedade; $\quad$ sociedade/natureza; $\quad$ prática/estrutura; desenvolvimento/preservação; objetividade científica cartesiana/visão holísta e interdisciplinar.

Nesse sentido,

[...] o que temos visto é que, mesmo no âmbito dos movimentos ecológicos, este intento ainda está longe de ser alcançado. Entre as perspectivas ecológicas que buscam manter esta tensão, sem reforçar os reducionismos, permanece a questão dos diferentes modos de lidar com o dualismo, seja para colapsá-lo ou para reconfigurá-lo. [...] traçar o horizonte de compreensão destas relações é uma questão que permanece em aberto. Apresentando o problema de outro modo, o que também está posto aí é o tema da alteridade e do monismo. A pergunta, neste caso, é em que medida a negação de qualquer dualidade natureza e cultura, não resvalaria em uma perspectiva monista que pode levar ao colapso da alteridade? (CARVALHO; STEIL, 2009, p. 91).

Esse debate dentro da ambientalização de todas as esferas da universidade não é uma questão trivial, especialmente quando de um outro ponto de vista se traça uma referência às relações híbridas entre natureza e cultura. Em outros termos, está proposta uma mudança densa na concepção do relacionamento entre sociedade/natureza, uma vez que já não se trata de projetar a natureza como algo a distância ou como um objeto fora do sujeito social. O meio ambiente é parte constitutiva do cidadão, ou o ser humano é parte integrante ou um dos elementos do que consideramos como o ecossistema.

O Grupo de Trabalho para Ações do Meio Ambiente e Educação Ambiental (GTMA), que tinha o papel de articular, de forma organizada e planejada, ações de diversos setores que geram impacto ambiental nos campi, propôs um conjunto de diretrizes para a elaboração de uma Política Ambiental da universidade (UFRN, 2002). Alguns programas, a partir de 2003, por iniciativa da Superintendência de Infraestrutura (SIN), apontam para a solução de impactos ambientais das diferentes atividades desenvolvidas. Os programas considerados prioritários, à época, foram o de gestão integrada de resíduos e o de controle de qualidade da água, acrescidos com o de educação ambiental. Isso se deve em grande medida devido à verificação de que

a área ocupada atualmente pelo Campus apresentava cobertura vegetal nativa contínua com a do PEDN; desta vegetação original, restaram apenas alguns fragmentos florestais de tamanhos variados distribuídos irregularmente em meio às edificações. Esta vegetação remanescente é caracterizada por árvores e arbustos típicos de ecossistemas costeiros, inclusive da Mata Atlântica (SALES; LISBOA; FREIRE, 2009, p. 82).

Para combater tal "desertificação" está consolidado um horto para providenciar espécies nativas de repovoamento do território. Desse movimento nasceu o "Projeto Nativas no Campus" 
visando ao plantio de árvores da Mata Atlântica no campus da UFRN. Ao longo do tempo também se expandiu, junto com outros atores, a arborização e reflorestamento de espécies nativas em áreas originalmente de Mata Atlântica e atingindo até mesmo parte do Semiárido. Tais iniciativas possuem como meta proporcionar conforto e preservação, dentro de um processo que denominamos de educacional ambiental para o cuidado com os bens naturais.

O Programa de Educação Ambiental da UFRN (ProEA) foi iniciado em novembro de 2003 e tem o objetivo de incentivar a adoção de uma postura institucional e social responsável perante a problemática ambiental, com prioridade sobre as atividades que geram impacto ao ambiente nas suas dependências, visando ao fortalecimento da imagem de uma instituição com responsabilidades socioambientais. Diante de incertezas e de impactos ambientais, Giddens (1997) advoga a emergência da reflexividade institucional e que tal iniciativa tornou-se um elemento constituinte central das estratégias diante dos conflitos.

O Programa organiza-se em atividades de capacitação e de motivação, mobilização e formação de hábitos $^{12}$, que são oferecidas à comunidade universitária e à sociedade em geral visando técnicas e ações de foco socioambiental. Envolvem a organização e participação em eventos; a promoção de campanhas relacionadas ao planejamento e a gestão ambiental (em apoio aos programas e projetos da DMA), além de projetos de extensão universitária. Essas atividades, entretanto, encontram-se permeadas de tensões, o que constitui uma característica central da gestão socioambiental que deriva de adaptações institucionais baseadas em discursos, relações, negociações e práticas cotidianas.

As atividades de capacitação promovem o conhecimento e visam fornecer aos participantes uma visão global do conceito de sustentabilidade, trabalhando conteúdos referentes à gestão e educação ambiental, incluindo gerenciamento de resíduos sólidos; fundamentos e princípios da educação ambiental, elaboração e gerenciamento de projetos socioambientais, entre outros. Os cursos de extensão de educação ambiental, oferecidos semestralmente, atraem um público diversificado. De acordo com os técnicos responsáveis seriam atividades que despertam a observação, a cidadania e estimulam a práticas onde podem emergir um conhecimento crítico ${ }^{13}$ ou criativo ante os impulsos ao consumo.

\footnotetext{
${ }^{12}$ Habitus em Bourdieu (1997; 2000) é um conhecimento adquirido e também um haver, ou seja, um capital (indica a disposição incorporada) do agente em ação (retoma o primado da razão prática), evidencia as capacidades criadoras, ativas, inventivas do agente. A sua gênese é o produto da interiorização dos princípios de um arbitrário cultural capaz de perpetuar-se e produzir ações e práticas. Habitus como "um corpo socializado, um corpo estruturado, um corpo que incorporou as estruturas imanentes do mundo ou de um setor particular desse mundo, de um campo, e que estrutura tanto a percepção desse mundo como a ação nesse mundo" (BOURDIEU, 1997, p. 124).

13 “[...] com base em uma análise dos recentes discursos acadêmicos e políticos sobre a criatividade, apresenta-se uma reflexão teórica sobre a necessária articulação dialética do pensamento crítico e criativo [...]” (TREMBLAY, 2011, p. 255). A respeito das dificuldades de manter uma crítica consequente, consulte Santos (1999) e Pacheco (2000).
} 
De alguma forma, pode-se endossar a visão de que o padrão de consumo de cada indivíduo (professor, funcionário ou discente) pode ser identificado como habitus; ao mesmo tempo representa a posição do indivíduo na hierarquia social da distribuição assimétrica dos resultados da produção social como apropriação da natureza. Nesse âmbito, parece fundamental o nexo entre habitus e espaço social, sendo compreensível que a busca por formação profissional é também um intuito por ascensão social e como tal maior acesso aos bens ofertados ou mercadorias em circulação no mercado. Ora, está manifesta a tensão entre as políticas de mitigação nos territórios e a força inebriante da cultura do consumo.

Em 2006, a Divisão de Meio Ambiente da SIN (DMA), além dos três programas iniciais, já havia incorporado um projeto de arborização para o Campus Central, outro de controle de zoonoses e proliferação de vetores, a Sala Verde (no âmbito do programa de mesmo nome do Ministério do Meio Ambiente) e a criação do Portal de Meio Ambiente. Essas são nitidamente iniciativas que incidem sobre a formatação dos territórios sustentáveis, uma vez que integram o processo de ambientalização em que se expandem as reflexões acerca das práticas das IES. Em 2015, foi iniciada a construção de uma nova casa de vegetação e um laboratório de botânica aplicada, para atender a ampliação do banco de sementes e do número de mudas produzidas para o programa de arborização da UFRN, além de qualificar o atendimento aos pesquisadores que desenvolvem atividades no horto da universidade. A Divisão de Meio Ambiente foi elevada, em fevereiro de 2011, à categoria de Diretoria e possui em seu quadro funcional 14 (quatorze) servidores, todos graduados e/ou pós-graduados, sendo dez deles com mestrado e dois doutorandos em suas áreas de atuação. Além disso, a diretoria conta com o apoio de cerca de 10 estagiários, de diversos cursos de graduação da UFRN e com cerca de 100 trabalhadores terceirizados responsáveis pela operacionalização do horto, da estação de tratamento de esgoto, da arborização (plantio, transplantio, irrigação e poda), controle de zoonoses, coleta seletiva solidária, cloração etc.

A planificação do campus da Unisinos teve, desde seu início, uma dimensão paisagística com a arborização, inclusive contando com a reconhecida experiência em pesquisa de botânica. $\mathrm{O}$ projeto Verde Campus, aprovado em 1997, está na gênese da política ambiental da Unisinos, incluindo as questões ambientais em processo contínuo da coleta de resíduos, o consumo de água e a preservação de áreas verdes, a coleta seletiva de papel, até atingir todas as rotinas de gestão ambiental. Em 2002, foi aprovado o projeto de busca da certificação ambiental do campus ${ }^{14} \mathrm{e}$ iniciou-se uma nova etapa, cuja política de sustentabilização rege as questões referentes à

\footnotetext{
${ }^{14}$ Silva e Drummond (2005, p. 02), ao discutirem as certificações a empresas, atestam que "A partir de uma série de indicadores é discutido não apenas se essas certificações contribuem para o desenvolvimento sustentável, mas também se são importantes para que essas organizações se mantenham competitivas [...] as certificações socioambientais inspiradas no desenvolvimento sustentável ainda têm um viés muito mais ecológico do que social”.
} 
preservação ambiental, aprovada em $1^{\circ}$ de abril de 2004 e revisada em 10 de novembro de 2009. O Sistema de Gestão Ambiental (SGA) ficou responsável pela coordenação das ações ambientais: a organização da coleta de lixo, a reciclagem, a redução do consumo de água e energia e do volume de resíduos gerados. De qualquer forma, os resultados encerram ou não revelam por suposto uma expressão das disputas entre diferentes estratégias políticas, orientadoras das atividades próprias da instituição universitária (MIRANDA, 2013).

Cabe destacar que em ambas universidades a alta administração destacou uma equipe com conhecimento técnico para coordenar o SGA, bem como as dimensões aqui em discussão. Existe uma portaria da reitoria que designou a coordenação, dando fluxo à criação do órgão institucional responsável por instaurar programas ou projetos ambientais. Esse encaminhamento tem como parâmetro de ação adequar normas para questões ambientais em consonância com uma política de sustentabilidade ambiental nos campi das universidades. A articulação entre agentes sociais, mediações e seus ambientes possibilita a análise dos espaços de conflito e dos processos de mudança atinentes ao campo ambiental.

O modelo de política ambiental das universidades perpassa algumas temáticas, entre elas a eficiência energética, os cuidados com os recursos hídricos, a regulamentação do uso de materiais impactantes, a gestão responsável, o consumo e descarte responsável, coleta seletiva e tratamento de esgotos. A articulação das atividades, atores sociais e processos decisórios contempla algumas dimensões, como a intencionalidade dos agentes sociais, o grau de formalização ou institucionalização dos projetos, bem como a apropriação pelos destinatários e, ainda, as estratégias para a obtenção de legitimação. Isso está em consonância com Miranda (2013, p. 144):

A análise das ações de grupos sociais que interagem por meio de discursos e estratégias que procuram legitimar e institucionalizar processos de regulação, acesso e uso de recursos naturais pode ser aprendida mediante a distinção de dois tipos de interdependência, uma que liga os membros do grupo e articula suas ações e outra que conecta todos os grupos que defendem diferentes projetos de apropriação e uso dos recursos naturais.

Os instrumentos adequados são relevantes para o processo de interiorização de cuidados com os bens ambientais e a consequente expressão em práticas sociais. Um dos principais mecanismos para as universidades demonstrarem o comprometimento com as questões ambientais se dá por meio da adoção de políticas institucionais e elaboração de um SGA que atenda às suas especificidades como um território sustentável. Parece consensual que uma ação com eficácia nessa área implica o envolvimento dos diversos setores/atores institucionais. 
A composição diversificada da comunidade acadêmica, com suas áreas de conhecimento, pode tanto ser um obstáculo e fraqueza devido à fragmentação, quanto potencializar o processo de construção de políticas ambientais, contribuindo para uma melhoria na qualidade ambiental do território da instituição. Lopes (2004, p. 34) também compreende como relevante o processo de institucionalização das questões ambientais, que está

associado a um processo de interiorização pelas pessoas e pelos grupos sociais - e, no caso da "ambientalização", dar-se-ia uma interiorização das diferentes facetas da questão pública do "meio ambiente". Essa incorporação e essa naturalização de uma nova questão pública poderiam ser notadas pela transformação na forma e na linguagem de conflitos sociais e na sua institucionalização parcial.

De fato, são fatores e atores internos que impulsionam a adoção, por parte das instituições, de medidas regulatórias visando territórios sustentáveis, que no médio e longo prazo conduziram à criação do reconhecido sistema de gestão ambiental. A noção de territórios sustentáveis possui uma presença no debate contemporâneo acerca das formas de ocupação do espaço e de "modalidades de organização com identidade cultural, de estilos de consumo responsável e de sistemas de gestão integrada, participativa e ecologicamente prudentes do patrimônio natural” (VIEIRA et al., 2009, p. 336).

A ênfase analítica a partir das ciências sociais nessas temáticas situa a política ambiental em um discurso pertinente acerca da responsabilidade social que se vincula à visão de gestão eficiente, compartilhada, integral, seja no âmbito de um território sustentável, seja como mecanismo de extensão a outros agentes com contatos diretos e indiretos. Portanto, as contribuições das universidades também se estendem na promoção de cursos de capacitação ou difusão da gestão ambiental visando atingir o conjunto amplo dos usuários. Nesse campo são perceptivos, de acordo com Castro, Hogenboom e Baud (2015, p. 14) "continuas tensiones y antagonismos acerca del acceso a los recursos naturales, la distribución y uso de los ingresos y la distribución, compensación y prevención de costos ambientales y sociales".

Ao longo da exposição certamente ficará evidenciado o fato de que as políticas implementadas pela gestão das universidades em estudo significam um reiterado esforço para uma adequação à legislação, bem como a produção de uma situação exemplar a outros espaços sociais e organizacionais ou a colaboração com a utopia de sustentabilização de todas as atividades na sociedade. Nesse sentido, são firmados diversos convênios, como no caso foi firmada parceria com os órgãos ambientais estaduais e municipais para reduzir equívocos e agilizar os processos de licenciamento ambiental relativos às atividades da UFRN e também melhorar a parte de fiscalização ambiental na instituição. 
Em razão de obstáculos e riscos à consolidação de territórios sustentáveis podemos acompanhar o entendimento de Leff (2014), ao encetar uma crítica a propósito de dificuldades em todas as áreas do conhecimento, em particular nas ciências sociais. Nessas últimas, por compreender tantas vezes a lógica da ordem social vigente de forma independente das condições de uma ordem inerente à natureza. Sem a devida junção das duas dimensões se constitui um projeto que destrói a sociedade como consequência. Os desdobramentos do processo de adesão às medidas ambientais geram de alguma forma um habitus ecológico (CARVALHO; STEIL, 2009), com os respectivos processos de identificação com uma causa legítima, instituindo um modo de vida subjetivo.

Para encerrar este tópico, uma referência ao nexo entre produção do conhecimento para iluminar práticas, mas também comentar equívocos relacionados às representações sociais dos agentes sociais:

ainda que a sociologia tenha por finalidade primeira o conhecimento e não a ação, pode fornecer instrumentos de compreensão do mundo social e preparar os agentes para lutar contra as várias formas de dominação. É função da sociologia contribuir para uma ação efetiva de emancipação, por meio do estudo das representações do mundo social e da elucidação do caráter arbitrário de certos esquemas de pensamento, difundidos e reproduzidos historicamente (VALLE, 2007, p. 127).

\section{Experiências de tratamento dos resíduos e gestão integrada}

A Lei Federal 12.305/2010 instituiu a Política Nacional de Resíduos Sólidos (PNRS), a qual assevera princípios, objetivos e instrumentos, bem como diretrizes relativas ao gerenciamento e à gestão integrada dos resíduos sólidos. Ainda afirma princípios com o intuito de assegurar medidas para territórios sustentáveis, além da cidadania e da inclusão social, por meio da geração de trabalho e renda. Nesse sentido, Besen et al. (2014, p. 261) conceituam e situam

A conceituação de gestão integrada e sustentável de resíduos implica numa hierarquia de objetivos que incluem: a minimização da geração de resíduos; a redução dos impactos negativos dos resíduos; a maximização da reutilização, da reciclagem e da compostagem; a recuperação de energia; a promoção de tratamento e a disposição final de forma ambientalmente segura.

Notadamente, as experiências de tratamento adequado dos resíduos, a partir da gestão integrada, possuem como sustentação uma proposta conceitual a partir de um novo paradigma para todas as questões que dizem respeito às dimensões da sustentabilidade ambiental. De acordo com a 
avaliação dos autores, as experiências abordadas consolidam um esforço amplo, em que se ambiciona que seja abraçado por todos os setores e agentes da universidade, além de implementar uma infraestrutura pautada pela ótica ambiental, aprimoram as condições de vida e relações sociais.

O conceito de ambientalização - e que outros autores preferem denominar como sustentabilização e o tema da educação ambiental no Brasil remetem à transversalização - pode ser entendido como a prática de internalizar a dimensão e a perspectiva da educação ambiental no cotidiano das pessoas e das instituições (LEFF, 2006; 2008). Importa reconhecer a complexidade da vigência de múltiplos saberes, valores e olhares na gestão do conhecimento acompanhada da criação de situações dialógicas e participativas, na construção de configurações subjetivas e objetivas das dificuldades e conflitos de apropriação, distribuição e descarte. Esses percalços da realidade em movimento permitem a Martínez-Alier e Walter (2015, p. 76) constatar que

Los conflictos ecológico distributivos emergen de las asimetrías estructurales en la distribución de las cargas de la contaminación y en el acceso a los recursos naturales que están enraizadas en una distribución desigual de poder e ingresos, así como en desigualdades sociales de origen étnico, de casta, de clase social y género.

As políticas ambientais e suas práticas requeridas na universidade estão sob o prisma de serem socialmente percebidas pela comunidade em termos gerais por mecanismos específicos de tradução. Para que um fenômeno seja socialmente percebido alarga-se o desafio devido aos múltiplos olhares e experiências. Um dos pontos de partida para a sensibilização para iniciantes compreenderem a relevância da dimensão ambiental pode surgir a partir da verificação de como anda a pegada ecológica de cada um no cotidiano.

É bem compreensível que ao olhar do leitor seria recomendável uma certa homogeneidade quanto às experiências no tocante ao tratamento dos resíduos líquidos e sólidos e da gestão integrada. O ideal de uniformizar os indicadores faz todo o sentido quando se trata da pretensão de permitir algum tipo de comparação entre os casos estudados. No presente caso essa não é uma impossibilidade, todavia a comparação pode desencadear uma concorrência ou competição para averiguar boas práticas ou a melhor experiência. Por essa razão, alternativamente, aqui se defende, de maneira incisiva, a abordagem de duas instituições a partir de indicadores ora similares, ora diferentes.

As pesquisas envolvendo a preocupação com as questões ambientais e a própria política ambiental engendrada proporcionaram outras abordagens em relação aos problemas do uso, da renovação e da degradação dos bens naturais, mostrando a busca de novos valores e outra ética para relações sociais com sustentabilidade. O texto de Venzke et al. (2012) relata sobre a experiência na gestão ambiental de duas instituições universitárias, reveladora da preocupação com a 
sustentabilidade e as políticas ou sistemas de gestão, que de alguma forma podem ser tidas como referência no Brasil e para difundir experiências positivas ao redor do mundo. A presença da dimensão ambiental na educação superior requer alguns requisitos:

a) exige formação adequada dos docentes e funcionários na atualização para desenvolver um trabalho baseado na interdisciplinaridade.

b) associa-se à onda do enfoque científico das disciplinas que têm sido influenciadas por um conjunto de fatores sociais visando à modernização, mas que raramente veio acompanhada de reflexões acerca do impacto da ciência e os riscos provenientes da tecnologia na sociedade.

c) almeja a institucionalização da questão ambiental, mirando um território sustentável compreendendo todos os usuários, os diversos níveis e modalidades de ação da universidade; isto tem se mostrado um desafio surpreendente, lançando atribuições sobre os mais diversos quadrantes das atividades, das práticas e políticas acadêmicas: ensino, gestão, pesquisa e extensão.

d) implica que os indivíduos no âmbito universitário adquiram a capacidade de compreender e avaliar os aspectos sociais, ambientais, políticos e éticos relacionados às inovações científicas e às aplicações tecnológicas na sociedade.

e) compreende a dimensão da sustentabilidade inserida nos diversos espaços universitários, pois, inclusive, no caso da forma da gestão do espaço, se manifestam reflexos na formação de futuros profissionais em todos os campos do conhecimento.

Atualmente, o saneamento ambiental exige ações abrangentes, integrando, entre outros aspectos, abastecimento de água, coleta e destinação adequada de resíduos sólidos e líquidos, organização das águas pluviais e gerenciamento da ocupação e uso do solo. A proposta de diretrizes para implantação de um sistema de gestão integrada de resíduos na UFRN data de 2004 (MEDEIROS, 2007). Com data similar, o mesmo ocorre na Unisinos. Essas diretrizes consistem em um conjunto de ações, planos, programas e normas destinados a promover e regular a gestão integrada dos resíduos classes I e II gerados ${ }^{15}$ pelos campi e usualmente conta com o apoio de um espaço e unidade de armazenamento temporário de resíduos. Na universidade mencionada, os resíduos sólidos classe I gerados no campus são descartados na Central de Resíduos da universidade juntamente com os outros resíduos perigosos. Alguns desses possuem um procedimento, a seguir descrito por Gomes e Esteves (2012, p. 383).

a Unisinos tem contrato com a Empresa 4 para recolhimento e tratamento (por incineração) de seus resíduos de serviços de saúde. A universidade gera animais mortos contaminados e outros resíduos de ambulatório, além de perfurocortantes

\footnotetext{
${ }^{15}$ Entende-se por resíduos de classes I e II os assim classificados pela NBR 10004/2014, da ABNT. O transporte e o local de depósito requerem licenciamento para um adequado sistema de controle de fluxo.
} 
(gerados no ambulatório e alguns laboratórios de pesquisa). A geração média mensal é de $100 \mathrm{~kg}$ de RSS, sendo que o investimento é de R \$130,00 por mês. São feitos dois descartes mensais. O valor médio, para descartes eventuais, é de $\mathrm{R} \$$ 3,10 por $\mathrm{kg}$ de $\mathrm{RSS}$, acrescido de $\mathrm{R} \$ 120,00$ como taxa de transporte (dados informados pela empresa para o Sistema de Gestão Ambiental da Unisinos).

Conforme Medeiros (2010), na UFRN o programa de gestão de resíduos objetiva

reduzir e controlar os impactos causados sobre o ambiente pelos resíduos produzidos pela UFRN em suas atividades de ensino, pesquisa e extensão, assegurando a melhoria contínua das condições de segurança, higiene e saúde ocupacional da comunidade universitária, colaborando com a qualidade de vida da população do seu entorno, com a preservação ambiental e a manutenção da vida no planeta.

A coleta, transporte e destinação final dos resíduos sólidos classe II (sólidos comuns não recicláveis) gerados nas unidades de Natal são realizadas em carro coletor próprio da instituição, e esses resíduos destinam-se ao aterro sanitário da Região Metropolitana, no município de Ceará-Mirim, tendo recebido, a partir de 2008, Licença Simplificada do Instituto de Desenvolvimento Sustentável e Meio Ambiente (GOMES, 2009). O lixo hospitalar é incinerado por meio de empresa licitada. Em 2009, 2010 e 2011 foram destinados ao aterro sanitário, respectivamente, 518,15; 492,36; e 689,58 toneladas de resíduos sólidos (GOMES, 2009). No ano de 2014 foram destinadas 884 toneladas, representando um acréscimo de 10,2\% em relação a 2012, quando foram destinadas 802 toneladas (UFRN, 2015). Atualmente, visando aprofundar a ambientalização com a afirmação de territórios sustentáveis, a gestão universitária está iniciando tomada de preços para destinação de RCC a usinas de reciclagem e para compra de agregados reciclados para utilização nas obras da UFRN.

A coleta seletiva na UFRN tem um histórico que remonta a 2002, quando um grupo de estudantes do curso de engenharia química, com o apoio da Divisão de Serviços Urbanos da SIN, iniciou uma coleta semanal de papel em alguns setores da instituição. Naquela época, apesar do direcionamento feito, todo tipo de resíduo reciclável era coletado. Dados da DSU (2004) apontavam que, do material coletado, apenas $6 \%$ era papel, $31 \%$ plástico, $21 \%$ latas, $2 \%$ vidro e $40 \%$ eram orgânicos e não recicláveis, havendo uma perda de $51 \%$ do material reciclável.

Atualmente, em atendimento ao Decreto no 5.940/2006, os resíduos sólidos recicláveis (não perigosos) são coletados pela própria instituição, armazenados na Unidade de Armazenamento Temporário de Resíduos (UATR) e destinados a duas cooperativas de catadores de materiais recicláveis da cidade de Natal, em sistema de rodízio, que fazem a triagem e recolhem os resíduos no local, duas vezes por semana. Em 2014, foram entregues às cooperativas 133,8 toneladas de resíduos recicláveis, o que representa um aumento de 8,2\% em relação ao mesmo período de 2013 
(123,6 toneladas); com um rendimento médio aumentando de 90,5\% para 91,7\%, cujo detalhamento pode ser verificado na tabela 1 .

TABELA 1 - RESÍDUOS RECICLÁVEIS DESTINADOS ÀS COOPERATIVAS ENTRE 2011 E 2015 EM KG E RENDIMENTO MÉDIO ANUAL (\%)

\begin{tabular}{c|c|c|c|c|c|c|c|c|}
\hline Ano & Papel/Papelão & Plástico & Metal & Vidro & Cartucho & Total anual & Rejeito* & Rendimento** \\
\hline $\mathbf{2 0 1 1}$ & $54.156,44$ & $4.074,90$ & 5.359 .50 & $3.351,30$ & 879.20 & $67.821,34$ & 6768.5 & $90.93 \%$ \\
\hline $\mathbf{2 0 1 2}$ & $88.691,30$ & $7,137.70$ & $3,802.60$ & $1.111,70$ & 82.40 & $112,162.60$ & $11,336.90$ & $89.89 \%$ \\
\hline $\mathbf{2 0 1 3}$ & $94.490,50$ & $8,996.30$ & $6,944.30$ & 511,10 & $1,354.10$ & $123,688.50$ & $11,392.20$ & $90.79 \%$ \\
\hline $\mathbf{2 0 1 4}$ & $103.930,10$ & $11,526.80$ & $6,096.70$ & 683,40 & 349,40 & $133.872,40$ & $11.286,00$ & $91.57 \%$ \\
\hline $\mathbf{2 0 1 5}$ & $98.780,65$ & $9.765,39$ & $9.862,87$ & 789,50 & 520,00 & $119.718,41$ & $4.380,00$ & $95,50 \%$ \\
\hline
\end{tabular}

FONTE: UFRN (2015).

*Encaminhado ao aterro sanitário e contabilizado na pesagem final desse tipo de resíduo.

**Aproveitamento dos resíduos recicláveis encaminhados à UATR, excluindo o rejeito após triagem (média anual).

Em 2015 observou-se uma redução na quantidade de resíduos recicláveis destinados às cooperativas, na ordem de $8 \%$, entretanto houve um aumento considerável no rendimento, passando de $91,57 \%$ para $95,50 \%$. Ainda não ocorreu uma investigação mais aprofundada acerca das causas dessas ocorrências, mas a principal hipótese é que sejam consequência da implantação da Agenda Ambiental da Administração Pública (A3P), iniciada em 2014.

A licitação para destinação dos resíduos classe I é feita anualmente, e para uma quantidade fixa, razão pela qual não é possível dar vazão à quantidade real gerada na instituição. Segundo estimativas da gerência da UATR, em março de 2016, encontravam-se aguardando para destinação final adequada cerca de 40.000 lâmpadas e mais de 35 toneladas de resíduos químicos. Os resíduos eletroeletrônicos ainda são alienados e destinados a leilões públicos.

Cabe esclarecer um detalhe ao leitor, que contribui na busca do fortalecimento da justificativa para a opção de um diagnóstico a partir de dados empíricos de duas universidades: não se trata claramente de um estudo comparativo, mas antes de exposições relativamente independente das duas experiências institucionais. Estas, como tal, paradoxalmente possuem ritmos distintos e ao mesmo tempo testemunham iniciativas dignas a destacar. Assim, há a mobilização de variáveis distintas, outras vezes similares, para cada uma das instituições universitárias.

O gerenciamento integrado de todos os resíduos, especialmente sólidos e líquidos, possui implicações administrativas, financeiras, sociais, educacionais, operacionais e ambientais no sistema de gestão ambiental das universidades. O descaso ou a atenção à questão do manejo de resíduos implica diretamente numa possibilidade de avaliar as práticas sociais e conferir danos aos bens naturais, com evidentes repercussões em diferentes âmbitos para além do ambiental. Dados gerais do gerenciamento de resíduos da UFRN podem ser conferidos na tabela 2. 
TABELA 2 - DADOS GERAIS DO GERENCIAMENTO DE RESÍDUOS SÓLIDOS NA UFRN

\begin{tabular}{l|c|c|c|c|c|c|c}
\hline \multicolumn{1}{c|}{ TIPO DE RESÍDUOS } & $\mathbf{2 0 0 9}$ & $\mathbf{2 0 1 0}$ & $\mathbf{2 0 1 1}$ & $\mathbf{2 0 1 2}$ & $\mathbf{2 0 1 3}$ & $\mathbf{2 0 1 4}$ & $\mathbf{2 0 1 5}$ \\
\hline $\begin{array}{l}\text { Resíduos sólidos recicláveis } \\
\text { destinados às cooperativas (em } \\
\text { toneladas) }\end{array}$ & - & - & $74,61 * *$ & 112,316 & 123,70 & 133,87 & 119,72 \\
\hline $\begin{array}{l}\text { Resíduos sólidos não } \\
\text { recicláveis enviados ao aterro } \\
\text { sanitário (em } \\
\text { toneladas) }\end{array}$ & 518,15 & 492,36 & 689,58 & 802,02 & 838,63 & 884,93 & $1.031,162$ \\
\hline $\begin{array}{l}\text { Lâmpadas (todos os tipos e em } \\
\text { unidades) }\end{array}$ & - & - & - & - & $14.000^{*}$ & $23.000^{*}$ & $40.000^{* * *}$ \\
\hline $\begin{array}{l}\text { Resíduos químicos } \\
\text { laboratoriais diversos } \\
\text { (em toneladas) }\end{array}$ & - & - & - & - & 18 & 18 & $35^{* * *}$ \\
\hline
\end{tabular}

FONTE: UATR (2015); SIPAC (2016).

*Encaminhados à empresa licitada (licenciada) para destinação final adequada.

**Em 2011, foram triados pelas cooperativas $23,30 \mathrm{~kg}$ de tetra pak, entretanto, a partir de 2012 as cooperativas passaram a incluir esse tipo de material no rejeito por não ter mercado viável no estado.

***Armazenados da UATR, aguardando destinação final.

A exposição de dados empíricos quantitativos possui o intuito de apontar as possibilidades de controle acerca dos fluxos de materiais como forma de atentar para as dimensões ambientais das atividades desenvolvidas e atestar o que afirmam Martínez-Alier e Walter (2015, p. 74)

Esta metodología provee una descripción de la dimensión física de la economía, donde el flujo de materiales del sistema socio-económico puede ser analizado históricamente o transversalmente a través de una contabilidad de los flujos de entrada (toneladas de biomasa, combustibles fósiles, minerales de construcción, minerales metálicos) o de salida (toneladas de materiales exportadas, residuos inertes o sustancias contaminantes generadas).

Os dados do gerenciamento de resíduos se inserem na tentativa de circunscrever a amplitude do processo de ambientalização, de tal forma que sejam exploradas as brechas para reflexões acerca das práticas ambientais nas IES, visando conformar territórios sustentáveis.

\section{TABELA 3 - RESÍDUOS SÓLIDOS COLETADOS NO CÂMPUS DA UNISINOS EM 2013 EM TONELADAS}

\begin{tabular}{c|c|c|c|c|c|c}
\hline Papel & Plástico & Metal & Vidro & $\begin{array}{c}\text { Total } \\
\text { reciclável }\end{array}$ & $\begin{array}{c}\text { Resíduos domésticos } \\
\text { não recicláveis }\end{array}$ & $\begin{array}{c}\text { Total } \\
\text { coletado }\end{array}$ \\
\hline 56,68 & 34,7 & 8,4 & 0,05 & 98,8 & 349,2 & 448 \\
\hline
\end{tabular}

FONTE: SGA (2013).

A tabela 3 apresenta as quantidades anuais geradas para reciclagem e destinadas à Cooperesíduos, bem como descarte de resíduos não recicláveis. Parece conveniente assinalar que os resíduos destacados no quadro acima possuem endereçamento distinto de acordo com as suas características, visando ao reaproveitamento. No que se refere aos resíduos domésticos não recicláveis, estes têm como principal destino a compostagem, com um tratamento para produção de 
adubação, que dessa forma retornam ao ambiente. Os resíduos vegetais são coletados e transferidos para a área da compostagem; devido à abundante arborização fica compreensível o grande volume gerado diariamente. Porém, sem desconhecer que há ainda uma parte que é destinada ao aterro sanitário, ou de outra forma, há processos que no momento ultrapassam a vontade política e a capacidade técnica de gestores e atores. Mesmo assim, é de suma importância cada qual fazer a sua parte em consonância com as políticas socioambientais.

Atividades experimentais com os materiais destacados nas tabelas 3 e 4 são realizadas no Laboratório de Resíduos Sólidos com o intuito de aprimoramento das técnicas e das políticas do setor ambiental. Essa é uma parte com destaque em infraestrutura, além de outros laboratórios de cursos que possuem a dimensão ambiental na própria denominação, para análises e instrumentalização para caracterizar amostras. As tecnologias possuem atribuições com significados contrapostos. Se de um lado consolidam-se como recurso contra a degradação e os impactos ambientais, de outro estão no centro da geração de rejeitos que agravam as questões de cuidado com os bens naturais. Para Giddens (1997), o nexo entre as relações sociais e a natureza possui imbricações decorrentes da ciência e da tecnologia, âncoras da modernização e ao mesmo tempo circunscrevem rupturas nos modos de vida.

Há que se reconhecer o impacto das mudanças decorrentes devido ao uso das tecnologias, especialmente informacionais. Estas se impõem pela forma como se combinam as técnicas e ocupam a lógica da agenda na vida cotidiana das pessoas, mas vale recordar que mais como influências, e menos como determinações.

TABELA 4 - CONTROLE DO GERENCIAMENTO DE RESÍDUOS SÓLIDOS NA UNISINOS

\begin{tabular}{l|c|c}
\cline { 2 - 3 } & $\mathbf{2 0 1 1}$ & $\mathbf{2 0 1 3}$ \\
\hline Baterias de nobreak - sucata de informática & 1920 & 945 \\
\hline Lâmpadas fluorescentes e/ou com vapor de mercúrio & 5.767 & 7.544 \\
\hline Óleo vegetal usado & 5.344 & 6.547 \\
\hline Papel vendido para reciclagem & 42.162 & 56.696 \\
\hline Resíduos químicos laboratoriais diversos - SÓLIDOS (1) & 3.210 & 3.133 \\
\hline Resíduos químicos laboratoriais diversos - LÍQUIDOS & 1.867 & 2.212 \\
\hline Resíduos sólidos domésticos - RECICLÁVEIS (2) & 123.030 & 98.861 \\
\hline Resíduos sólidos domésticos - NÃO RECICLÁVEIS (2) & 298.000 & 349.261 \\
\hline
\end{tabular}
FONTE: UNISINOS (2011; 2013).

(1) enviados pra a Cettrel - Central de Tratamento de Efluentes Líquidos.

(2) enviados à Cooperesíduos - Cooperativa de Catadores de Resíduos e Prestação de Serviços.

A tabela 4 atesta que: está em curso a obsolescência planejada, cuja ótica se evidencia pelo descarte brutal e corriqueiro de baterias, material de informática e lâmpadas fluorescentes; a substituição das lâmpadas fluorescentes, compactas e/ou tubulares, apesar do menor consumo de energia elétrica, tem dificuldades de atender ao apelo de preservação ambiental, por precisar, em 
sua fabricação, de substâncias impactantes quando do descarte delas, no caso o mercúrio, utilizado em lâmpadas fluorescentes, e vapor de mercúrio. Os milhares de litros de óleo vegetal usado anualmente recolhidos são destinados a uma cooperativa de economia solidária para produção de uma variedade de produtos artesanais de baixo custo para uso na limpeza com maior teor ecológico, gerando uma economia ambiental com a diminuição do consumo de produtos de limpeza industrializados, além de ser um complemento monetário a famílias de baixa renda. A insistência na política de redução do uso e descarte do papel nas atividades burocráticas da administração tem dificuldades de declinar com certa velocidade, já que os meios eletrônicos vêm substituindo parcialmente a sua finalidade, ao mesmo tempo em que a quase totalidade do papel descartado pode ser reciclado; os resíduos não recicláveis ainda superpõem em muito a lógica reversa. Nesse sentido,

As mudanças em andamento parecem um percurso importante para compreender alterações da mercantilização e do consumo como uma prática social na sociedade contemporânea. Entre as virtudes inerentes à mercadoria destacam-se a aparência estética e a obsolescência planejada pela velocidade da circulação do capital. Com a ajuda da informática, a criação de mercadorias se ajusta rapidamente para responder às flutuações do mercado. A fluidez e o descarte fazem o suceder veloz de protótipos de mercadorias, que por sua vez são associadas à colonização do imaginário, à sensualidade, aos instintos. Está configurado um processo em que a aceleração da obsolescência é parte do planejamento estratégico, que por sua vez conjuga os princípios de diferenciação, de renovação e de declínio da exigência de durabilidade (RUSCHEINSKY, 2010, p. 240).

Entre os resíduos sólidos domésticos, localizamos o fenômeno da sociedade de descarte e que engendra a governança ambiental num contexto histórico e ambiental como um processo social, de acordo com a compreensão de Castro, Hogenboom e Baud (2015). Muitas vezes é de menor custo financeiro e conveniente comprar um artefato novo do que consertar ou fazer um upgrade no computador antigo. Essa é a lógica da obsolescência programada, mensagem constantemente reafirmada pelos apelos da publicidade e um fenômeno relacionado ao tempo útil de um bem ou produto que é planejado para durar por um curto período de tempo. No final de 2010, foi estabelecida uma meta para reduzir $10 \%$ da emissão de CO2 dentro da Unisinos no período de um ano e melhorar a qualidade ambiental no campus. O objetivo nasceu dentro de um movimento internacional e motivou diferentes áreas da universidade a desenvolver ações específicas.

Na pesquisa com o intuito de localizar dados acerca da gestão, fica evidenciado que os relatórios também evoluem e se modificam na forma de exposição, dificultando a organização de séries de dados. Para o tratamento de efluentes laboratoriais da Unisinos, há diversas etapas e 
processos até chegar ao seu destino no descarte ${ }^{16}$. No campus São Leopoldo, certos efluentes passam por um pré-tratamento para separar metais pesados que, por sua vez, destinam-se a aterros de resíduos perigosos, o que se conforma para tornar-se um território sustentável. O efluente líquido é processado na Estação de Tratamento de Esgoto própria, com capacidade de retirar a maior parte dos contaminantes e possui um lugar específico do ponto de vista geográfico e do ponto de vista da avaliação referente ao SGA. Outros efluentes e resíduos sólidos perigosos, que não podem ser tratados dessa forma, são estocados, atendendo à legislação vigente e enviados para tratamento fora da universidade.

Igualmente, na UFRN, a coleta e armazenamento temporário de resíduos classe I (resíduos perigosos), para posterior destino final, são feitos a partir da solicitação dos setores. A destinação final desses resíduos é realizada por empresa licitada a um custo bastante elevado para a universidade, tendo em vista que somente empresas do Sul e Sudeste atendem à chamada. Em 2014 foram destinadas 18 toneladas de resíduos químicos e 23.000 lâmpadas fluorescentes tubulares (UFRN, 2015). Em 2015 não foi aberta nenhuma licitação.

Entretanto, existe um projeto em execução para a construção de um laboratório para tratamento preliminar dos resíduos químicos, o que irá reduzir os custos atuais de destinação final. Essas iniciativas possuem diversos outros benefícios, como afirmam Costa et al. (2015, p. 240)

a coleta dos resíduos químicos, quando comparada às atividades que serão realizadas no laboratório, mostra que a implantação deste é viável ambientalmente e socialmente pelo fato de reciclar, recuperar e reutilizar os reagentes químicos, sem a necessidade de extração de novos recursos. Isto também minimiza a disposição de resíduos químicos no meio ambiente, reduzindo os riscos de contaminação de áreas. Além disso, colabora para a formação acadêmica dos alunos, oferecendo oportunidades de pesquisas e estágios. Concomitantemente, a implantação do laboratório elimina a necessidade de processos licitatórios para tratamento e encaminhamento dos resíduos gerados na universidade, além da eliminação do risco assumido do princípio da corresponsabilidade; além de que atende às necessidades impostas por alguns dos princípios do Plano de Logística Sustentável na Administração Pública Federal.

Os programas de gestão de resíduos nos territórios das universidades em destaque consolidam um reconhecimento de que "la vida útil de los productos se reduce para evitar una saturación de mercado y ello lleva a una gran generación de residuos y desechos que contaminan el ambiente" (SEJENOVICH, 2015, p. 240). Ou ainda, como afirmam Martínez-Alier e Walter (2015, p. 75), "las opiniones optimistas relacionadas con la modernización ecológica, la

\footnotetext{
${ }^{16}$ A formulação de planos e programas nem sempre está amplamente divulgada ao público. A propósito da coleta de efluentes, organização por setores, tratamento de resíduos, há mais informações no site: http://unisinos.br/blogs/energiapositiva/page/2/\#sthash.1Q84UWI4.dpuf.
} 
'desmaterialización' de la economía (Stern, 2004), se enfrentan con las tendencias actuales del aumento del consumo de energía y materiales en la economía mundial, procesos que aumentan la producción de residuos y fomentan los conflictos ecológico distributivos”. Ao mesmo tempo, a alusão a resultados positivos a que os dados permitem inferir refere-se aos esforços por meio de programas atinentes à redução do consumo de energia, água, papel e outros gêneros.

\section{Indicadores de qualidade ambiental e o controle de qualidade da água}

Os autores, no presente caso, não possuem uma determinação para referir-se ao uso de indicadores físico-químicos da qualidade da água, embora se faça alusão às consistentes circunstâncias de tipos de poluição química da água, com despejos ácidos e óleos, entre outros. O controle da qualidade da água requer uma avaliação que se relaciona à dimensão social da disponibilidade para o consumo humano de forma universal, do incremento do saneamento básico como fator de saúde pública ${ }^{17}$. Em ambas as universidades há nítido dimensionamento quanto à responsabilidade da instituição educacional no tocante a essa temática.

Nas atuais circunstâncias, constata-se um paradoxo que influencia também a questão ambiental: de um lado um regime de gestão obcecado pela competitividade com medições, controles, eficiência, indicadores de desempenho, procedimentos de auditoria e ajuste econômico; de outro um alinhamento à universidade para os cidadãos, com ratificação de cuidados com os bens ambientais e a geração de conhecimento socialmente engajado. O fetiche dos indicadores está transformando a ciência, por vezes até distorcendo o que não é mensurável ou não se ajusta ao olhar da vigilância e controle diante da degradação ambiental.

Na pesquisa e observação de campo, constatamos algo que parece paradoxal na medida em que se difunde a proposta de gestão ambiental com participação compartilhada e integrada e, de outro lado, o requisito de um órgão centralizado de coordenação, gestão e controle. A abrangente institucionalização da dimensão ambiental reporta-se à presença cotidiana na gestão, ensino, pesquisa e extensão, (des)envolvendo a comunidade interna e se estendendo ao exterior do campus.

\footnotetext{
17 "O fracasso do saneamento básico e a emergência de doenças vetoriais", In: http://www.ihuonline.unisinos.br/, em cuja página se destacam, entre outras dimensões: "sem saneamento não há controle epidemiológico eficaz"; "vontade política e articulação intersetorial no enfrentamento das epidemias" e ainda "equivocada a política de saúde pública apoiada no uso de venenos no combate ao Aedes aegypti; é preciso encarar o desafio do saneamento ambiental no Brasil".
} 
Dentro da produção acadêmica ${ }^{18}$, é reconhecida a sobrecarga ou uso além da capacidade de regeneração do planeta: usamos/consumimos os bens naturais (não) renováveis.

O Campus Central da UFRN é abastecido por solução coletiva alternativa de abastecimento, composta por um conjunto de sete poços artesianos, enquanto a área da saúde e as unidades isoladas são abastecidas pela concessionária local (Caern). Tal solução deu-se pelo fato de na época de sua construção, no final dos anos de 1960 e início dos anos 1970, o campus central encontrar-se bastante distante da área urbanizada de Natal. Na Unisinos, todo abastecimento é feito pela concessionária local (Semae), que mesmo tendo problemas recorrentes com a interrupção do fornecimento, deliberadamente declinou de poços artesianos por compreender que a água é um bem universal.

O controle da qualidade da água no Campus Central da UFRN foi iniciado em 2001 por iniciativa da SIN, em parceria com alguns professores do Departamento de Química, ocasião em que foi constatado que os níveis de nitrato estavam, em 4 das 6 áreas do campus, acima do limite máximo permitido pelo Ministério da Saúde.

Como as técnicas disponíveis para reduzir os níveis de nitrato em grandes volumes de água são de alto custo, a solução adotada foi a diluição entre águas de poços. Esse controle teve periodicidade anual até 2004 quando, para atender aos parâmetros de qualidade dispostos na Portaria n ${ }^{\circ}$ 518/04-MS, foram incluídas análises físico-químicas em 23 pontos de coleta do Campus Central. Em 2006 foi elaborado, em parceria com o Setor de Vigilância Ambiental municipal, um plano de amostragem para o controle da qualidade da água destinada ao consumo humano no Campus Central, que incluía a análise físico-química e microbiológica em 60 pontos de coleta, estrategicamente planejados, e considerando o Plano Diretor do campus. Desde 2013, a coleta e análise físico-química e microbiológica são feitas por empresa terceirizada, tendo em vista que a SIN/DMA não possui técnicos para atender à demanda atual de pontos de coleta e análise, ficando responsável pela atualização dos Protocolos de Operação Padrão (POP) e aferimento (diário) de funcionamento e eficiência de equipamentos de sanitização da água (cloradores).

A questão da água está emergindo como um grande dilema no cotidiano, seja quanto à credibilidade, seja quanto a ser um direito e, por outro lado, pelos problemas socioeconômicos e ambientais cada vez mais complexos no nível macro. A política de sustentabilidade para a pesquisa, a gestão e o ensino lida agora para além de outros desafios, de acordo com Sotoudeh (2012), como também com o fato ou problemas como o aumento dos riscos ambientais e de segurança, o aumento

\footnotetext{
${ }^{18}$ Martínez-Alier e Walter (2015, p. 96) corroboram esta perspectiva: "recientemente, universidades y proyectos de investigación también se han involucrado con estas actividades de sistematización. Algunos esfuerzos se proponen mapear los conflitos ambientales en un país".
} 
do consumo de recursos e as oportunidades desiguais do uso de novas tecnologias decorrentes de efeitos adversos de inovações técnicas.

Las adaptaciones institucionales implican estrategias desarrolladas por diferentes actores para aumentar su capacidad para ser incluidos o para definir las "reglas del juego" en la gobernanza ambiental. Estas adaptaciones incluyen diversos mecanismos, desde la reforma discursiva y las nuevas estrategias de comunicación a las iniciativas innovadoras y la integración de conocimientos y tecnologías. (CASTRO; HOGENBOOM; BAUD, 2015, p. 29).

A cultura urbana, na qual se situam os agentes da sustentabilidade ambiental, direciona ações para uma racionalização do cotidiano, porém está implicada em ambiguidades para considerar a natureza como patrimônio cultural. Para a eficiência das políticas de saneamento básico, a convicção de parte relevante dos cidadãos constitui parte do resultado como um consenso possível, como desfecho de negociações e com o desempenho do poder público. A defesa da biodiversidade mostra quão importantes são os saberes diversos, o saber laico, entre outros, para preservá-la.

Uma questão relevante a propósito do controle da qualidade da água e o comprometimento com o descarte com declínio dos impactos sobre os recursos hídricos referem-se à existência de Estação de Tratamento de Esgotos (ETE) da UFRN e da Unisinos. A poluição do lençol freático, devido à infiltração de esgotos sanitários não tratados na cidade de Natal, configura-se como o principal problema de contaminação da água para consumo humano. O sistema de esgotamento sanitário do Campus Central é composto por aproximadamente $7 \mathrm{~km}$ de rede coletora, Estação de Tratamento de Esgotos (ETE) e reuso do efluente tratado. O projeto da ETE foi elaborado no final da década de 1970, iniciando sua operação em 1981, tendo como objetivo destinar adequadamente os efluentes sanitários gerados no Campus Central, eliminando os sistemas de fossas sépticas e sumidouros que contaminam o solo e o lençol freático. Cabe citar que nos últimos três anos está em curso um projeto de ampliação da capacidade coletora, especialmente tendo em vista a adequação de um território sustentável diante da expansão arquitetônica da universidade.

O tratamento é realizado em valo de oxidação com decantação secundária. A escolha por essa concepção de tratamento baseou-se nas seguintes vantagens: pequena área para implantação, custo inferior aos sistemas convencionais, elevada eficiência na remoção de DBO e sólidos em suspensão, lodo mineralizado que dispensa a digestão anaeróbica, fácil operação e manutenção, e dispensa decantação primária. O efluente tratado é utilizado na irrigação das áreas verdes e dos campos de futebol do Campus Central. Essa prática condiz com as medidas de mitigação a que se refere Miranda (2013, p. 156): "tem estado muito presente nas agendas de pesquisa das últimas duas décadas, em relação à apropriação e uso coletivo de recursos naturais de maneira sustentável e à 
mitigação dos impactos ambientais por meio da reciclagem e do descarte adequado dos resíduos sólidos".

Pela Estação de Tratamento de Esgoto (ETE) da Unisinos, são tratados aproximadamente $500 \mathrm{~m}^{3}$ de efluentes domésticos diariamente, atendendo à legislação ambiental, por um processo biológico, tanto anaeróbio quanto aeróbio, e de desinfecção ${ }^{19}$. O monitoramento é feito a partir da coleta semanal de amostras, organizadas pelo Sistema de Gestão Ambiental (SGA), e integra o relatório anualmente, em forma de dados, entregue ao órgão municipal responsável pela renovação da licença de operação da universidade. Em 2011, a universidade investiu no aprimoramento da ETE e instalou sistemas complementares ou uma atualização tecnológica. Beecroft e Dusseldorp (2012) vão referir-se a um aprendizado para compreender e avaliar os impactos da tecnologia como potencial para a metodologia de formação em temas ambientais. A pesquisa acerca da avaliação desses impactos consolida-se como um domínio que se desenrola com a parceria que remonta às ciências sociais, à filosofia da ciência e à ética. Esse processo de investigação e de aprendizagem se viabiliza com o posicionamento institucional.

A UFRN aderiu em 2013 às diretrizes A3P (Agenda Ambiental na Administração Pública). Esta agenda busca a construção de uma nova cultura institucional nos órgãos e entidades públicos, de estímulo aos gestores para a incorporação de princípios e critérios de gestão socioambiental em suas atividades rotineiras, levando à economia de recursos naturais e à redução de gastos institucionais por meio do uso racional dos bens públicos, da gestão adequada dos resíduos, da licitação sustentável e da promoção da sensibilização, capacitação e qualidade de vida no ambiente de trabalho que, em síntese, se reporta às questões relacionadas à interação da organização institucional com o meio ambiente. As autoras Souza, Uhlmann e Pfitscher (2015, p. 133) sintetizam esta proposição:

OMMA, por meio de uma iniciativa do Governo Federal, criou a A3P, que é aplicável à administração pública direta e indireta nas três esferas de governo: municipal, estadual e federal. O objetivo é inserir e debater questões sobre o desenvolvimento sustentável de organizações públicas. De acordo com o MMA (2009), a A3P é um programa de caráter voluntário que se propõe a inserir critérios ambientais nas áreas de governo, visando minimizar ou eliminar os impactos ao meio ambiente provocados por atividades administrativas ou operacionais.

Também, a partir de 2015, a instituição está trabalhando no Plano de Logística Sustentável (PLS), de que trata a Instrução Normativa $\mathrm{n}^{\circ}$ 10, de 12 de novembro de 2012, instituído através do

\footnotetext{
${ }^{19}$ A ETE conta com grade, caixa de areia, reator UASB, reator CBR, decantador, sistema de ozonização (que elimina microrganismos) e leitos de secagem. Mais informações em: http://goo.gl/z8XSxU.
} 
art. 16 do Decreto $\mathrm{n}^{\circ}$ 7.746, de 5 de junho de 2012, para consolidar um território sustentável que, em outros termos, pode ser considerada uma política ambiental para a universidade.

Alguns outros encaminhamentos aludem à sustentabilidade ambiental e à biodiversidade nos projetos de políticas ambientais de cuidado com as águas e com referência a um caos que possui as respectivas contradições. Diante das circunstâncias do controle da qualidade da água, cabe esclarecer a vigência de um fluxo destrutivo e outro criativo. $\mathrm{O}$ aspecto destrutivo representa a desmontagem ou a erosão de parte importante da biodiversidade como um recurso irrecuperável pela simples razão de que a sociedade não consegue mitigar os efeitos letais. Ao mesmo tempo, em todo caos encontra-se a gênese em que desponta a face generativa ou iniciativas que a médio prazo produzem efeitos por vezes em conflito com o processo de modernização ou urbanização ${ }^{20}$. Diante da voracidade produtivista e consumista, bem como da tecnificação, a dinâmica da natureza, nos limites de suporte dos ecossistemas, responde com tufões, tsunamis, enchentes ou secas, terremotos e uma incontida mudança climática.

A referência às dificuldades para a compreensão e a conformação dos territórios sustentáveis remete ao modo como pedagogicamente são transmutados por forças divergentes os imaginários sociais. As proposições de políticas ambientais dentro das universidades alargarão a sua relevância na medida em que estudarem a pertinência dessa noção como fonte e origem de se aventar opções de constituir outras práticas concretas diante do processo de degradação ambiental.

No transcorrer do presente artigo não foi apresentada uma exaustiva discussão sobre as barreiras e dificuldades para gerar territórios sustentáveis. De um lado, observa-se nas Instituições de Ensino em tela preocupante diligência no que concerne à observação de dispositivos legais. De outro, existe um amplo leque de solicitudes conflitantes, como a formação para o mercado de trabalho competitivo e o empreendedorismo em cujo horizonte os bens ambientais são meros subsídios para alavancar os processos.

A comunicação ambiental possui em ambas as universidades um canal na web que permite tanto oferecer informações a respeito da documentação ao público interessado quanto o recebimento e o atendimento das solicitações de professores, funcionários, discentes, prestadores de serviços e comunidade externa com relação às questões pertinentes ao SGA. Inclusive no formulário

\footnotetext{
${ }^{20}$ Entre projetos de larga envergadura, cite-se o Projeto VerdeSinos, que desde 2008 se propõe à recomposição da mata ciliar da bacia do Rio dos Sinos. O apoio da Unisinos dá suporte às ações de preservação e recuperação por meio da pesquisa, além de cursos de educação ambiental. Conta atualmente com leque amplo de parcerias: Comitesinos, produtores rurais, Ministério Público, Emater, Irga, sindicatos rurais, prefeituras e outras entidades da região, mobilizando mais de 6 mil pessoas em 21 municípios da região. Talvez convenha frisar que precedeu essa iniciativa de ação permanente para reverter a degradação ou ausência da vegetação ribeirinha o Projeto Monalisa, que entre 2004 e 2006 mapeou quase 3 mil quilômetros de córregos, arroios e rios da região.

Fonte: http://www.comitesinos.com.br/2015/02/saiba-mais-projeto-verdesinos/.
} 
disponível há campo próprio para os diferentes agentes mencionados, entre eles pedidos de informações, comunicações de órgãos de fiscalização, reclamação de possíveis problemas, ocorrência ambiental e outros casos. É a tecnologia digital a serviço da celeridade para a circulação de dados e subsídios para alterar práticas sociais.

Portanto, na crítica feita aos aspectos perversos das inovações tecnológicas, longe se vai de uma perspectiva de retorno ao passado. As relações sociais nunca mais serão as mesmas devido às transformações da base fisico-químico-ecológica de forma profunda. O processo de caos está presente de uma forma recorrente, por mais que não se queira admitir tal horizonte, ao mesmo tempo em que se perdeu a sustentabilidade da reprodução das formas de vida. Dados objetivos não faltam para atentar para mudanças do olhar cultural a respeito das práticas e questões socioambientais nas quais se entrelaçam a investigação, políticas públicas e atores sociais. A perspectiva do antropocentrismo como cultura predominante difunde-se e ampara-se no discurso que ressalta privilégios individuais e consumistas, em vez de avalizar direitos e bens sociais garantidos a toda sociedade. O meio ambiente e o patrimônio cultural não são troféus que possam ser disputados e conquistados.

A crise ambiental propriamente dita ampara a sua entrada na história contemporânea marcando os limites da cultura alicerçados na racionalidade (LEFF, 2006) e na pretensão de sonhar com a felicidade a partir da satisfação de desejos de apropriação material. Quanto aos efeitos dos impactos, implica destacar questionamentos no interior de políticas ambientais, reconhecendo que alguns indivíduos e grupos sociais, países ou regiões encontram-se afetados de forma diferenciada mais que outros pela insustentabilidade dos processos de apropriação da natureza, pelos riscos ambientais e tecnológicos.

Das políticas ambientais se requer a produção de dados confiáveis visando à sua legitimação, e como tal precisam ser monitorados e controlados. As universidades correm o risco de serem conquistadas e colonizadas pelo frenesi da inovação tecnológica; ao mesmo tempo há o requisito de projetos de visibilidade que apontem para o público externo a sua função social. Porém, a realidade ambiental, com ganhos singelos diante da imensidão dos impactos em curso, não se presta a cultuar índices e rankings a serem publicados e comemorados como gloriosas posições galgadas. A posição nas planilhas determina a sorte de pesquisadores e de departamentos. Importa tanto a quantidade dos efeitos quanto a qualidade; a performance é uma dimensão secundária.

Para concluir, as experiências no campo ambiental vão se refletir em termos de elaboração de uma tradição ou de ritualização na vida cotidiana, menos como algo estático e mais como um fenômeno em constante mutação. Nesse sentido, “a tecnologia, no significado geral da 'técnica', desempenha aqui o papel principal, tanto na forma de tecnologia material quanto da especializada 
expertise social (GIDDENS, 1997, p. 77). Seja no plano cotidiano, seja no plano global, precisamos contemplar um contexto que podemos caracterizar como deslocamento de significados e como (re)apropriação de especialidades.

A consulta aos resultados expressos em relatórios das universidades dá conta das orientações para a sustentabilidade evidenciadas nas políticas de gestão e nas referências a práticas ordinárias de controle a respeito dos impactos ambientais. Outros temas importantes referidos à sustentabilidade estão nas políticas em relação a uma governança ambiental, operações comerciais, pesquisa e sensibilização da comunidade ${ }^{21}$.

Algumas das diferentes óticas relativas às contribuições ou aportes da Unisinos e, em certa medida, da UFRN, pelo exposto até aqui, a propósito de estabelecer territórios com as características da sustentabilidade, no caso, ocorreu a partir da apropriação de três referências expostas por Hidalgo (2015): a) Perspectivas de contribuição direta e de alguma forma derivadas de impactos percebidos: criação de uma unidade específica para coordenar as ações visando à sustentabilidade, geração de mecanismos de participação, sistema de gestão ambiental (SGA), oficinas de sua difusão, planejamento estratégico, plano de ordenamento verde para o campus, diagnóstico, controle, monitoramento dos serviços ambientais. b) Aspectos envolvendo uma contribuição extensiva ou indireta, que afeta a todos os indivíduos, porém de maneira especial os estudantes e os fornecedores, uma vez que estes são uma extensão da sociedade ou podem ser tidos como incorporados às relações sociais, aos serviços e ao mercado laboral. A difusão de competências entre os estudantes evidentemente decorre, entre outros fatores ou mecanismos, dos programas com debate ambiental na grade curricular, promoção de atividades de participação e apropriação de um espaço ordenado de acordo com arbitragem ambiental. Cabe neste caso uma imagem conhecida de outras paisagens: uma correia de transmissão. Contudo, esse fluxo pode evidentemente alternar-se em ambas as direções. Por isso, a exigência de determinadas práticas e a educação para competências ambientais consolidam-se em fator fundamental da contribuição da universidade, bem como em uma porta de apreensão das formas como a sua política ambiental é socialmente percebida e apropriada. c) Ações de extensão da universidade como uma contribuição mais do que simbólica em coletivos de temáticas ambientais, com ações derivadas de participação ou projeção para além de seu próprio território ou de uma instituição com visibilidade socioambiental exercendo a sua função social. Usualmente são circunstâncias em que a

\footnotetext{
${ }^{21}$ Vaughter (2016, p.17), ao referir-se a uma pesquisa no Canadá, resume: “Os resultados sugerem que a maioria das políticas de sustentabilidade se inscreve a Brundtland e à orientação dos três pilares. Muitas políticas de sustentabilidade também se ligam a políticas municipais ou estaduais externas. Em termos de vários domínios da sustentabilidade, as operações do campus foram discutidas por todas as políticas e com mais detalhes, enquanto as discussões a propósito da sustentabilidade na educação (ou seja, o currículo) e na pesquisa eram vagos, e as discussões em relação à sensibilização da comunidade foram incluídas com menos frequência".
} 
universidade é convidada a ter assento na medida em que possui expertises que têm muito a dizer como um ator social relevante à sociedade regional. São exemplos desta dimensão a inserção e participação em foros, conselhos, congressos, movimentos, fundações, comissões, gestão de espaços naturais protegidos, entre outros de distinta índole.

\section{Considerações finais}

O crescimento vivenciado pelas universidades nos últimos anos, com o surgimento de novos cursos, aumento do corpo docente, discente e técnico e a ampliação do espaço físico, trouxe também um aumento nos impactos ambientais causados pelas atividades desenvolvidas, como os decorrentes da geração dos mais diferentes tipos de resíduos e de efluentes líquidos, e pelo consumo de bens naturais ou serviços ecossistêmicos, entre outros. Portanto, a maneira pela qual a instituição executa suas atividades cotidianamente é uma importante demonstração das maneiras de adquirir responsabilidade com a sustentabilidade e reforçar valores, comportamentos e atitudes desejados na comunidade inteira.

Por outro lado, considerando que a maioria dos municípios do Rio Grande do Norte e do Rio Grande do Sul tem menos de 30.000 habitantes (IBGE, 2010), iniciativas bem-sucedidas de territórios sustentáveis desenvolvidas nas universidades seriam passíveis de adaptação para grande parte dos municípios e para além de suas fronteiras. Todavia, convém atentar para o fato de que a realidade do local é consecutivamente relativa, na medida em que se encontra inscrita num contexto mais amplo, por vezes pode ser determinada por suas conexões com o contexto. A abordagem da dimensão de territórios sustentáveis coloca o desafio de manter ao mesmo tempo uma abertura ampla para peculiaridades do particular e uma capacidade de examinar a inscrição do universal numa especificidade local, bem como o movimento inverso. Nesta pesquisa se procurou abordar as políticas de sustentabilidade nas universidades como trajetórias locais e cujo sentido emerge em termos de realidades singulares. Todavia, por mais que seja paradoxal, também aludimos à influência de dimensões societárias e estruturais a respeito da realidade dos campi universitários.

O intuito, ao longo das seções do texto, foi descrever o estado atual do conhecimento ambiental, do planejamento, das práticas em curso, bem como das barreiras às políticas ambientais. Ao mesmo tempo, além dos conteúdos da formação profissional de acordo com os respectivos cursos, pode-se também mencionar que o planejamento e a performance das políticas abrem brechas para novos horizontes quanto aos cuidados com os bens naturais. Nesse ínterim, as tensões estão 
manifestas uma vez que há o desafio de atualizar as informações aos discentes ${ }^{22}$ para uma ação consequente, cujo público tem curta passagem por esse espaço. A expansão de políticas ambientais possui na velocidade da depredação ambiental um concorrente robusto.

Para além dessa dimensão prática acima citada, imaginamos que as reflexões arroladas no texto nos permitem aludir a outras publicações de repercussão internacional e que dizem respeito à temática socioambiental. Entre essas mencionamos Leme (2012), Venzke et al. (2012), Ruscheinsky (2014), cujos objetivos confluem para: documentar e disseminar as experiências de universidades em avançado processo de transversalização da questão ambiental; fomentar o intercâmbio de informações sobre a aplicação de projetos nos diversos setores institucionais; apontar abordagens metodológicas e teóricas que se reportam ao tema inseridas nos currículos.

A confirmar, as críticas aos programas vinculados à sustentabilidade em parte se devem à perspectiva ligada a um projeto modernizador da universidade, por meio da expansão de uma racionalidade que se constrói com a negação da existência de outras formas de cultura ou de saberes (LEFF, 2006; 2008). Nasce daí a interrogação a respeito do espaço de uma esfera pública, para a expressão plural ou pluridiversidade, na qual inclusive as expressões místicas e religiosas possuem o espaço de expressão.

Em forma de síntese, a transversalização dos temas ambientais nos espaços das universidades onde se realizou o levantamento de dados significa: a) perceber e incorporar a questão ambiental como relevante na gestão, pesquisa, ensino e extensão; b) conseguir realizar a incidência na esfera do cotidiano das relações institucionais ou mesmo projetar uma contribuição global; c) compreender, participar e contribuir na resolução de problemas ambientais no seu próprio espaço como no nível regional; d) dar concretude à preocupação ambiental nas atividades cotidianas, inclusive no consumo, descarte e uso das tecnologias; e) conformar a formação de um "campo de possibilidades", marcado pela pluralidade das ações, projetos, olhares e que tendam a ser também concorrências; f) acolher a dialética de que se inicialmente essa concorrência acirra as fronteiras institucionais, contraditoriamente também serve para elidir as mesmas fronteiras. As práticas sociais ou relações sociais são o âmbito próprio da radicalização de políticas ambientais, mas também passam pelo planejamento, pela articulação institucional e por diagnósticos.

As apostas acima mencionadas passam pelo reconhecimento de que o largo uso de sistemas informacionais consolida redes de compartilhamentos múltiplos e influenciam as escolhas dos

\footnotetext{
${ }^{22}$ Em face da PNRS, Domigues et al. (2014) afirmam: "percebe-se pouco enfoque de estudos que avaliem o conhecimento e conscientização dos cidadãos, um dos atores envolvidos na gestão compartilhada dos resíduos sólidos. Neste contexto, o objetivo deste trabalho foi investigar a consciência dos discentes de Administração a respeito da Política Nacional de Resíduos Sólidos [...] no entanto, constatou-se que práticas relacionadas à educação ambiental ainda são necessárias".
} 
sujeitos em face das práticas sociais de teor ambiental. Este se conforma em um campo de possibilidades e de conflitualidades em significados múltiplos de cada cidadão fazer a sua parte ou negociação permanente para a conformação das políticas ambientais. Tendo observado os processos de gestão das universidades pesquisadas, podemos concluir que as tecnologias utilizadas condicionam e projetam a regularidade de ações e de metas. Da mesma forma, ressalta-se que atividades cotidianas se transformam positivamente em rituais com reuniões, práticas sociais e coleta de dados e, como tal, em um habitus que evidenciam apropriação e a capacidade criativa dos agentes sociais, tornando-se constante a continuidade de sua utilização, bem como de sua avaliação e inovação.

O debate e as propostas de implementar a dimensão ambiental se politiza por vias diferentes e com objetivos diversos em conformidade com a promoção por uma universidade socialmente comprometida, especialmente por intermédio de agentes com capacidade decisória nas instituições. As escalas espaciais dos campi universitários e os contextos sociais, políticos, simbólicos e econômicos parecem igualmente condicionantes a destacar quando se trata da gestação de territórios sustentáveis.

Entre as muitas razões para a inserção da temática ambiental, estão: a) melhoria da imagem da instituição no intuito de mostrar à sociedade que a instituição compreende suas responsabilidades socioambientais no cuidado com os bens ambientais e com práticas coletivas de sustentabilidade; b) a construção de uma cultura ambiental no cotidiano dos relacionamentos dentro das instituições: adequação à legislação vigente e dar o exemplo a outros atores sociais com inovação no cenário; c) economia de recursos no processo em consequência do uso planejado e sustentável; d) preocupação diante dos riscos na economia de recursos, mercantilização ou o risco de escassez.

A inserção da dimensão ambiental situa-se também como um parâmetro estratégico na defesa e ampliação da democracia, na promoção da inclusão social e dos direitos, na incorporação da dimensão antropológica e no âmbito da formação profissional como cultura com as respectivas práticas sociais e simbólicas. Destaque-se, nesse caso, a inequívoca correlação entre ambientalização nas esferas da universidade e da sociedade, ou seja, um contexto histórico e ambiental do processo social, porquanto a universidade não se solidifica como uma ilha, pois sua função realiza-se nas interfaces.

A aproximação cotidiana para um dimensionamento de aspectos ambientais nas práticas cotidianas da vida universitária gera um ideário ecológico. Este ideário adquire maior consistência se for acompanhado de um processo em que se rompe com o dualismo assim posto: de um lado a modernização em que cujo horizonte está suposto a submissão da natureza à razão instrumental; de outro o princípio de retorno à natureza e de respeito à capacidade de reprodução dos ecossistemas. 
Interrogação interessante relaciona-se ao fato de que os protestos cotidianos, seja no ensino formal ou nas conversações cotidianas, contra as injustiças sociais vão desembocar ou associar-se a críticas relacionadas às injustiças hídricas ou à defesa de direitos universais e aos bens naturais como um bem comum. Essa circunstância é uma oportunidade para conferir as conflitividades em curso e socialmente percebidas. Sendo assim, dentro da produção acadêmica essa circunstância serve para a construção de inventários ou mapeamentos de conflitos em torno de temáticas ambientais. Trata-se de mais um link para estabelecer vínculos com redes sociais de ativistas que trabalham as mesmas perspectivas fora das universidades e sofrem com os impactos das adversidades.

\section{Referências}

BESEN, G. R. et al. Coleta seletiva na Região Metropolitana de São Paulo: impactos da Política Nacional de Resíduos Sólidos. Ambiente \& Sociedade, v. 17, n. 3, p. 259-278, 2014.

BILERT, V.S.S. A educação ambiental na universidade: um estudo nos cursos da área das ciências sociais aplicadas nas Instituições de Ensino Superior Públicas (IES) no Paraná. Pato Branco: UTFPR, 2013.

BOURDIEU, P. Razões práticas: sobre a teoria da ação. Campinas: Papirus, 1997.

BOURDIEU, P. O poder simbólico. 3. ed. Rio de Janeiro: Betrand Brasil, 2000.

CARVALHO, I.C.M.; STEIL, C. A. O habitus ecológico e a educação da percepção: fundamentos antropológicos para a educação ambiental. Educação \& Realidade, v. 34/3, p. 81-94, 2009.

CASTRO, F; HOGENBOOM, B; BAUD, M. Gobernanza ambiental en América Latina en la encrucijada. In: CASTRO, F; HOGENBOOM, B; BAUD, M. (Coords). Gobernanza ambiental en América Latina. Buenos Aires: CLACSO; ENGOV, 2015.

COSTA, L. T. et al. Laboratório de tratamento e recuperação de resíduos químicos: alternativa para resíduos industriais do sul de Minas Gerais. Revista Brasileira de Desenvolvimento Regional, v. 2, n. 2, p. 225-243, 2015.

DIVISÃO DE SERVIÇOS URBANOS (DSU). Destino dos Resíduos Sólidos Recicláveis Gerados pela comunidade UFRN. Natal: UFRN, 2004.

DOMINGUES, G. S. et al. Consciência dos discentes do curso de administração de uma universidade federal acerca da PNRS. FÓRUM INTERNACIONAL DE RESÍDUOS SÓLIDOS, 5., 2014, São Leopoldo. Anais... São Leopoldo: Unisinos, 2014. Disponível em: <http://goo.gl/Fi71Cq>. Acesso em: 20 set. 2015. 
GIDDENS, A. A vida em uma sociedade pós-tradicional. In: BECK, U; GIDDENS, A; LASH, S. Modernização reflexiva: política, tradição e estética na ordem social moderna. São Paulo: Editora da Unesp, 1997.

GOMES, L; ESTEVES, R. V. R. Análise do sistema de gerenciamento dos resíduos de serviços de saúde nos municípios da bacia hidrográfica do Rio dos Sinos. Engenharia Sanitária Ambiental, v. 17, n. 4, p. 377-84, 2012.

GOMES, M. P. S. Plano de Gerenciamento de Resíduos Sólidos Comuns da Universidade Federal do Rio Grande do Norte - PGRSC/UFRN: Campus Natal. Natal: UFRN, 2009.

IBGE. Cidades@. Disponível em: < http://goo.gl/t2KsaF>. Acesso em: 15 abr. 2015.

FOLLARI, R. Estudios culturales, transdisciplinariedad e interdisciplinariedad (¿Hegemonismo en las ciencias sociales latinoamericanas?). Utopía y praxis Latinoamericana, v. 6/14, p. 40-49, 2001.

FOLADORI, G; TAKS, J. Um olhar antropológico sobre a questão ambiental. Mana, v. 10/2, p. 323-348, 2004.

HALAC; R. M.; MARCHISIO, M. Los campus universitarios como espacios de producción y multiplicación de la construcción sustentable. I Encontro Latino Americano de Universidades Sustentáveis (I Elaus). Passo Fundo/RS, 2008. Disponível em: <http://goo.gl/MOVbqS >. Acesso em: 07 maio 2015

LEFF, E. Discursos sustentables. México: Siglo XXI, 2008.

LEFF, E. Racionalidade ambiental. A reapropriação social da natureza. Rio de Janeiro: Civilização Brasileira, 2006.

LEFF, E. La apuesta por la vida. Imaginación sociológica e imaginarios sociales en los territorios ambientales del sur. México: Siglo XXI, 2014.

LEME, P. C. S et al. (Orgs.). Visões e experiências ibero-americanas de sustentabilidade nas universidades. Madrid: Gráfica Alhambra, 2012.

LIMONAD, E. A insustentável natureza da sustentabilidade. Da ambientalização do planejamento às cidades sustentáveis. Cadernos Metrópole, v. 15, n. 29, p. 123-142, 2013.

LOPES, J. S. L. A ambientalização dos conflitos sociais: participação e controle público da poluição industrial. Rio de Janeiro: Relume Dumará, 2004.

LÓPEZ, J. L. A.; ALVISO, C. R.; ROSAS, J. B. Metodología para la transversalidad del eje medio ambiente. Revista Iberoamericana de las Ciencias Sociales y Humanísticas, v. 3/6, p. 1-20, 2015.

MARTÍNEZ-ALIER, J.; WALTER, M. Metabolismo social y conflictos extractivos. In: CASTRO, F.; HOGENBOOM, B.; BAUD, M. (Orgs). Gobernanza ambiental en América Latina. Buenos Aires: CLACSO; ENGOV, 2015. 
MATHIEU, N. Pour une construction interdisciplinaire du concept de milieu urbain durable, Natures Sciences Sociétés, v. 14, n. 4, p. 379, 2006.

MEDEIROS, M. F. S.; GOMES, M. P. S. Programa de Gestão Integrada de Resíduos da UFRN. Natal: UFRN, 2010.

MEDEIROS, M.F.S. Divisão de Meio Ambiente: Relatório de atividades 2006. Natal: UFRN, 2007.

Ministério DO MEIO AMBIEnTE. Agenda Ambiental da Administração Pública. 5. ed. Brasília: SAIC, 2009.

MIRANDA, R.S. Ecologia política e processos de territorialização. Sociedade e Estado, v. 28, n. 1, p. 142-161, 2013.

PACHECO, J.A. Reconceptualização curricular: os caminhos de uma teoria curricular crítica. Perspectiva, v. 18, n. 33, p. 11-34, 2000.

PARQUE DAS DUNAS. Disponível em: < http://goo.gl/n9RZal>. Acesso em: 15 abr. 2015.

ROBBINS, P. Political ecology: a critical introduction. 2. ed. Oxford: Blackwell Publishing, 2012.

ROPOHL, G. Der didaktische Ort transdisziplinären Wissens: additive und integrative Strategie In: BEECROFT, R; DUSSELDORP, M (Eds.). Technikfolgen abschätzen lehren. Heidelberg: VS Verlag für Sozialwissenschaften, 2012.

RUSCHEINSKY, A. Informação, meio ambiente e atores sociais: mediação dos conflitos socioambientais. Revista Ciências Sociais Unisinos, v. 46, p. 232-247, 2010.

RUSCHEINSKY, A. et al. (Orgs.). Ambientalização nas instituições de educação Superior no Brasil: caminhos trilhados, desafios e possibilidades. São Carlos: USP/São Carlos, 2014.

SALES, R. F. D.; LISBOA, C.M.C.; FREIRE, E.M.X. Répteis squamata de remanescentes florestais do campus da Universidade Federal do Rio Grande do Norte, Natal-RN, Brasil. Cuadernos de herpetología, v. 23/2, p. 77-88, 2009.

SANTOS, B. de S. Porque é tão difícil construir uma teoria crítica? Revista Crítica de Ciências Sociais, Coimbra, n. 54, p. 197-215, 1999.

SANTOS BRAZ, R. F. et al. Estudo sobre os aspectos socioeconômicos dos catadores de resíduos recicláveis organizados em cooperativas na cidade de Natal-RN. REMEA - Revista Eletrônica do Mestrado de Educação Ambiental, v. 31, n. 2, p. 147-159, 2014.

SEJENOVICH, H. La estrategia para superar la pobreza a través del desarrollo sustentable. In: CASTRO, F.; HOGENBOOM, B.; BAUD, M. (Orgs.). Gobernanza ambiental en América Latina. Buenos Aires: CLACSO; ENGOV, 2015.

SGA UNISINOS. Relatório 2013. Disponível em: <http://goo.gl/3akqdI>. Acesso em: 29 set. 2015

SILVA, M.A.R.; DRUMMOND, J.A. Certificações socioambientais: desenvolvimento sustentável e competitividade da indústria mineira na Amazônia. Cadernos EBAPE, v. 3, n. 3, p. 01-21, 2005. 
SOTOUDEH, M. Neue Schwerpunkte für die technische Ausbildung im 21. Jahrhundert. In: BEECROFT, R; DUSSELDORP, M (Eds.). Technikfolgen abschätzen lehren. Heidelberg: VS Verlag für Sozialwissenschaften, 2012.

SOUZA, V.D.; UHLMANN, V.O; PFITSCHER, E. D. Sustentabilidade ambiental em instituição de ensino: aderência à Agenda Ambiental de Administração Pública. Perspectivas Contemporâneas, v. 10, n. 1, p. 126-145, 2015.

TREMBLAY, G. Criatividade e pensamento crítico. Intercomunicação. Revista Brasileira de Ciências da Comunicação, São Paulo, v. 34, n. 1, p. 255-266, 2011.

UFRN. Diretrizes para uma Política de Qualidade Ambiental para a UFRN. Natal: UFRN, 2002.

UFRN. Relatório de Atividades 2014: Diretoria de Meio Ambiente. Natal: UFRN, 2015.

VALLE, I.R. A obra do sociólogo Pierre Bourdieu: uma irradiação incontestável. Educação e Pesquisa. v. 33, n. 1, p. 117-134, 2007.

VAUGHTER, P.et al. Campus sustainability governance in Canada: a content analysis of postsecondary institutions sustainability policies. International Journal of Sustainability in Higher Education, v. 17/1, p.16-39, 2016.

VENZKE, C. S. et al. environmental management on university campuses in southern Brazil. In: LEAL, Walter (Org.). Sustainable development at universities: new horizons. Frankfurt, v. 34, p. 885-898, 2012.

VIEIRA, P. F. et al. Potencialidades e obstáculos à construção de territórios sustentáveis no estado de Santa Catarina. Política \& Sociedade, v. 8, n. 14, p. 335-382, 2009.

YÁNEZ, R. et al. Aproximación al redimensionamiento de la Ingeniería desde la perspectiva del desarrollo sustentable y el pensamiento omplejo. Ingeniería Industrial, v. III, n. 11, p. 87-94, 2013.

Artigo recebido em 09/02/2016. Aceito para publicação em 03/06/2016. 